\title{
A strength-oriented exercise session required more recovery time than a power-oriented exercise session with equal work
} \author{
Solberg ${ }^{1}$, Gøran Paulsen ${ }^{\text {Corresp. } 1,3}$ \\ ${ }^{1}$ Norwegian Olympic and Paralympic Committee and Confederation of Sports, Oslo, Norway \\ 2 Polar Electro Oy, Kempele, Finland \\ 3 Department of Physical Performance, Norwegian School of Sport Sciences, Oslo, Norway \\ Corresponding Author: Gøran Paulsen \\ Email address: goran.paulsen@nih.no
}

Christian Helland ${ }^{1}$, Magnus Midttun ${ }^{1}$, Fredrik Saeland ${ }^{1}$, Lars Haugvad ${ }^{1}$, Daniela Schäfer Olstad ${ }^{2}$, Paul Andre

The present randomized cross-over controlled study aimed to compare the rate of recovery from a strength-oriented exercise session vs. a power-oriented session with equal work. Sixteen strength-trained individuals conducted one strength-oriented session ( 5 repetitions maximum (RM)) and one power-oriented session ( $50 \%$ of $5 \mathrm{RM})$ in randomized order. Squat jump (SJ), countermovement jump (CMJ), 20-m sprint, and squat and bench press peak power and estimated 1RMs were combined with measures of rate of perceived exertion (RPE) and perceived recovery status (PRS), before, immediately after and 24 and 48 hours after exercise. Both sessions induced trivial to moderate performance decrements in all variables. Small reductions in CMJ height were observed immediately after both the strength-oriented session ( $7 \pm 6 \%$ ) and power-oriented session ( $5 \pm 5 \%$ ). Between 24 and 48 hours after both sessions CMJ and SJ heights and $20 \mathrm{~m}$ sprint were back to baseline. However, in contrast to the power-oriented session, recovery was not complete 48 hours after the strength-oriented session, as indicated by greater impairments in CMJ eccentric and concentric peak forces, SJ rate of force development (RFD) and squat peak power. In agreement with the objective performance measurements, RPE and PRS ratings demonstrated that the strength-oriented session was experienced more strenuous than the power-oriented session. However, these subjective measurements agreed poorly with performance measurements at the individual level. In conclusion, we observed a larger degree of neuromuscular impairment and longer recovery times after a strength-oriented session than after a power-oriented session with equal total work, measured by both objective and subjective assessments. Nonetheless, most differences were small or trivial after either session. It appears necessary to combine several tests and within-test analyses (e.g., CMJ height, power and force) to reveal such differences. Objective and subjective assessments of fatigue and recovery cannot be used 
interchangeably; rather they should be combined to give a meaningful status for an individual in the days after a resistance exercise session. 
1 A strength-oriented exercise session required more recovery 2 time than a power-oriented exercise session with equal work

3

4 Christian Helland ${ }^{1}$, Magnus Midttun ${ }^{1}$, Fredrik Sæland ${ }^{1}$, Lars Haugvad ${ }^{1}$, Daniela Schäfer Olstad ${ }^{2}$, 5 Paul Andre Solberg ${ }^{1}$, Gøran Paulsen ${ }^{1,3}$ 6

$7 \quad{ }^{1}$ Norwegian Olympic and Paralympic Committee and Confederation of Sports, Oslo, Norway

$8 \quad 2$ Polar Electro Oy, Kempele, Finland

$9 \quad{ }^{3}$ Department of Physical Performance, Norwegian School of Sport Sciences, Oslo, Norway 10

11 Corresponding Author:

12 Gøran Paulsen

13 Norwegian School of Sport Sciences, Oslo, Norway

14 Sognsveien 220, 0806 Oslo, Norway

15 goran.paulsen@nih.no 
18

19

20

21

22

23

24

25

26

27

28

29

30

31

32

33

34

35

36

37

38

39

40

41

42

43

44

45

46

47

48

49

50

51

52

53

54

55

56

57

58

\section{Abstract}

The present randomized cross-over controlled study aimed to compare the rate of recovery from a strength-oriented exercise session vs. a power-oriented session with equal work. Sixteen strength-trained individuals conducted one strength-oriented session (5 repetitions maximum $(\mathrm{RM})$ ) and one power-oriented session (50\% of 5RM) in randomized order. Squat jump (SJ), countermovement jump (CMJ), 20-m sprint, and squat and bench press peak power and estimated 1RMs were combined with measures of rate of perceived exertion (RPE) and perceived recovery status (PRS), before, immediately after and 24 and 48 hours after exercise. Both sessions induced trivial to moderate performance decrements in all variables. Small reductions in $\mathrm{CMJ}$ height were observed immediately after both the strength-oriented session

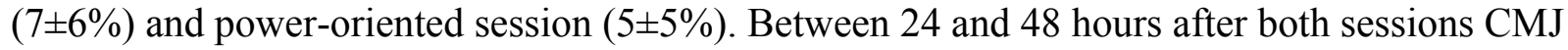
and SJ heights and $20 \mathrm{~m}$ sprint were back to baseline. However, in contrast to the power-oriented session, recovery was not complete 48 hours after the strength-oriented session, as indicated by greater impairments in CMJ eccentric and concentric peak forces, SJ rate of force development (RFD) and squat peak power. In agreement with the objective performance measurements, RPE and PRS ratings demonstrated that the strength-oriented session was experienced more strenuous than the power-oriented session. However, these subjective measurements agreed poorly with performance measurements at the individual level. In conclusion, we observed a larger degree of neuromuscular impairment and longer recovery times after a strength-oriented session than after a power-oriented session with equal total work, measured by both objective and subjective assessments. Nonetheless, most differences were small or trivial after either session. It appears necessary to combine several tests and within-test analyses (e.g., CMJ height, power and force) to reveal such differences. Objective and subjective assessments of fatigue and recovery cannot be used interchangeably; rather they should be combined to give a meaningful status for an individual in the days after a resistance exercise session.

\section{Introduction}

Athletes use different forms of resistance exercise (training) to improve muscle power output and sport performance, including heavy load strength-oriented exercises (e.g. $80 \%$ of 1 Repetition Maximum [1RM]) and low-to-moderate load power-oriented exercises (e.g. $~ 40 \%$ of $1 \mathrm{RM}$; (Newton and Kraemer, 1994)). In general, high-intensity resistance exercise challenges the ability to generate high forces, and with a conventional volume of exercise ( 5-15 sets per muscle group) neuromuscular fatigue develops during the sessions. This resistance exerciseinduced fatigue typically requires 1-3 days of recovery (Vincent and Vincent, 1997;Raastad and Hallen, 2000;Ahtiainen et al., 2003;2004).

The recovery process is obviously necessary for regaining full performance capacity, but it is also intertwined with adaptation processes, such as hypertrophy and increased efficacy of the metabolic pathways (Bishop et al., 2008;Paulsen et al., 2012;Cunanan et al., 2018). Recovery is therefore vital for all who perform resistance exercise, whether recreationally trained individuals or elite athletes. However, our knowledge of the recovery processes after resistance exercise is still inadequate, and we cannot accurately predict recovery times from a given exercise session 
59 (Bishop et al., 2008;Paulsen et al., 2012;Kellmann et al., 2018). The difficulty in predicting

60

61

62

63

64

65

66

67

68

69

70

71

72

73

74

75

76

77

78

79

80

81

82

83

84

85

86

87

88

89

90

91

92

93

94

95

96

97

98

99

recovery rates lies in the range of factors at play, including - but not restricted to - type of muscle contractions, relative load (\% of maximal strength) and volume of work performed (i.e., load times displacement times number of repetitions).

Contraction velocities and the transition from the eccentric to the concentric phase differentiate the diverse forms of resistance exercise. Classical power-oriented exercise means using low to moderate loads (e.g., 30-50\% of 1RM) and the lifts are typically executed in a plyometric fashion; i.e., a fast transition from eccentric to concentric phase, and high (maximal effort) movement velocities (Newton and Kraemer, 1994;Suchomel et al., 2017). This contrasts with strength-oriented exercise, in which the transition between the eccentric and concentric phase is typically controlled and slow (due to the heavy loads used).

Surprisingly few studies have investigated the potential differences in recovery times between different forms of resistance exercise, such as strength-oriented exercise ( $>80 \%$ of 1RM) with slow velocities (mean velocity of the lifting bar $<0.6 \mathrm{~m} / \mathrm{s}$ ) and power-oriented exercise with low/moderate loads ( $<50 \%$ of $1 \mathrm{RM}$ ) lifted with high velocities (mean velocity of the lifting bar $>1 \mathrm{~m} / \mathrm{s}$; (Banyard et al., 2018; Garcia-Ramos et al., 2018b)).

Linnamo et al. (1998) compared recovery rates after 40\% of 10RM with 100\% of 10RM (5 sets and 2-minute rest periods) in the knee-extension exercise, applying a crossover design in nonresistance trained individuals. Using an isometric strength test, the authors demonstrated less acute fatigue and faster recovery from the power-orientated exercise compared to the heavy-load exercise over 48 hours. Similarly, but studying elite track and field athletes, Howatson et al. (2016) found a reduction in isometric strength 24 hours after heavy-load strength-oriented session ( $4 \times 5$ repetitions; squat, split squat and push press), but not after power-orientated session (30\% of the heavy load; 4 x 5 repetitions; speed squat, split squat jump and power press). However, with different exercise volumes (same total number of repetitions, but different loads), it is not possible to tease out the true impact of the load. McCaulley et al. (2009) controlled for exercise volume and reported greater acute neuromuscular fatigue after heavy-load squats than after maximal power jump squats. However, there was no difference in the recovery between the strength-oriented session and power-orientated session after 24 and 48 hours (McCaulley et al., 2009). In a similar study, Hiscock et al. (2018) compared heavy loads (90\% of 1RM; $3 \times 3$ reps) against "power loads" (45\% of 1RM; $3 \times 6$ reps) in squat and deadlift with equal volume between exercise modes. No differences were found between experimental loads; however, recovery was seemingly complete within 12 hours after the power-oriented session, while 24 hours were required after the heavy-load session. In short, our knowledge of the impact of loads on recovery after different modes of resistance exercise is limited and requires further study.

Recovery can be defined as normalisation of neuromuscular function (Bishop et al., 2008). However, it is not always obvious which function(s) should be measured. In the McCaulley et al. (2009) study, the participants conducted a dynamic squat exercise, but an isometric squat was used to assess neuromuscular function. Hence, it seems reasonable to question whether a dynamic test, such as squat jump (SJ) or countermovement jump (CMJ), would have displayed similar recovery rates. Indeed, when a range of recovery tests have been applied, such as CMJ,

Peer) reviewing PDF | (2020:03:46939:2:0:NEW 1 Sep 2020) 
100

101

102

103

104

105

106

107

108

109

110

111

112

113

114

115

116

117

118

119

120

121

122

123

124

125

126

127

128

129

130

131

132

133

134

135

136

137

138

139

140

sprinting and single joint isokinetic torque, the tests do not demonstrate interchangeable recovery courses (Andersson et al., 2008; Chatzinikolaou et al., 2010). Apparently, different recovery rates may also be seen between variables extracted from the same test. For example, decrease in mean power has been shown to recover faster than the increased duration of the concentric phase of the CMJ (Gathercole et al., 2015a).

To confidently track the time course of recovery, dealing with the error of measurements is a challenge. Impairments of muscle strength and power are typically observed in the range of $\sim 5$ $20 \%$ immediately after resistance exercise in trained individuals, but may be less than 5\% below baseline after 24 hours (Raastad and Hallen, 2000;Howatson et al., 2016;Hiscock et al., 2018). Knowing that the typical error (coefficient of variation; CV) in day-to-day measurements of CMJ and SJ height and power is at best 3-5\% (Raastad and Hallen, 2000;Hopkins et al., 2001; Gathercole et al., 2015a), the sensitivity of vertical jump tests may be limited for monitoring the final part of the recovery process. In the present study we address the typical error of all tests applied and explore the sensitivity of different variables extracted from SJ and CMJ (including jump height, peak power and peak force).

Exercise load and work, neuromuscular fatigue and recovery can be assessed not only with objective performance measures (strength and power tests; as discussed above), but also subjectively, using rate of perceived exertion (RPE) and perceived recovery status (PRS). Perceived exertion has been used for years with endurance exercise (Borg, 1970), but also for resistance exercise (Foster et al., 2017); while the PRS scale has a shorter history (Laurent et al., 2011). Subjective measures are simple and convenient to use, but what do they tell us? The use of and correlation between objective and subjective measures of recovery and performance monitoring have been debated for years (Scott et al., 2016;Foster et al., 2017).

Interestingly, few investigations have compared subjective and objective recovery assessments after different forms of resistance exercise. Sikorski et al. (2013) observed a relationship between PRS and the muscle damage marker creatine kinase 48 hours after a conventional, high-volume resistance exercise session; however, no measure of muscle function was included. Korak et al. (2015) observed that recreationally strength-trained males experienced faster recovery, measured with PRS, from single-joint compared to multi-joint exercises, which appeared to correspond to changes in 10RM-tests (objective tests). Unfortunately, the study lacked appropriate objective measures of recovery; i.e., tests of maximal force and power. In a case study of three weightlifters/powerlifters, Zourdos et al. (2016) found that daily 1RM lifts consistently improved performance over 37 days, but the improvement seemed inadequately reflected in RPE and PRS scores. Although case studies of high-level athletes are interesting, such studies provide only weak evidence. This leaves us with the conclusion that more research is needed to elucidate the relationship between objective and subjective measures of recovery after different forms of resistance exercise.

The aim of the present study was to compare the recovery rates from a power-oriented session with a heavy-load strength-oriented session of similar work. A range of objective performance tests of strength and power were combined with subjective tests (RPE and PRS) to acquire a broad picture of the recovery processes in both upper and lower body muscles. We hypothesized 
141 that the power-oriented session would induce less performance decrements than the strength-

142 oriented session at all time points; and, consequently, that complete recovery would occur within

14348 hours for the power-oriented session but not the strength-oriented session.. Secondly,

144 compared to the strength-oriented session, we hypothesized that the participants would perceive

145 the power-oriented session as less strenuous and to experience a better recovery status after 24

146 and 48 hours. Finally, we hypothesized that changes in RPE and PRS would be numerically

147 related to changes in objective measures, such as the SJ and CMJ.

148

149 Materials \& Methods

150 Study design

151 The present study was a randomized cross-over study where each participant completed a heavy-

152 load, strength-oriented session and a moderate-load, power-oriented session, in randomized order

153 (applying the Research Randomizer; Urbaniak and Plous (2013)). To achieve a counterbalanced

154 order, the participants were paired, so that one started with the strength-oriented session and one

155 with the power-orientated session. One to four weeks of rest were allowed between sessions

156 (16 \pm 10 days (mean \pm standard deviation)).

157 A test battery of physical performance tests and evaluation of perceived effort and recovery

158 status was applied before, immediately after, and 24 and 48 hours after the exercise sessions

159 (Figure 1). The concentric work (J) performed in the first session was recorded and replicated in

160 the second session, ensuring equal work in both sessions. The exercises were the same for both

161 sessions, but somewhat adapted to serve the purpose of the sessions (Table 1). The primary aim

162 of the study was to compare the recovery rates between sessions when all factors were equal

163 except the external load (50\% lower in the power-oriented session than the strength-oriented

164 session).

165

166

167

168

169

170

171

172

173

174

175

176

177

178

179

*** Figure 1 and Table $1 * * *$

Three to seven days before the first exercise session, a familiarization session was conducted. The participants were familiarized with all tests and exercises (see details below) and instructed not to conduct any strenuous exercise 48 hours prior to the test days. The participants were also instructed to standardize their breakfast before and their meals after the exercise sessions (for 48 hours). All supplements and medications were prohibited during the study period.

During the exercise sessions the participants were given a protein bar and a protein drink (both supplements containing approximately $20 \mathrm{~g}$ protein, $30 \mathrm{~g}$ carbohydrates, and a total of $\sim 1000 \mathrm{KJ}$ (Yt, Tine, Oslo, Norway), and an energy drink ( $30 \mathrm{~g}$ carbohydrates; $510 \mathrm{KJ}$; Yt, Tine, Oslo, Norway) to ensure sufficient protein and energy intake (in total: $40 \mathrm{~g}$ protein and $90 \mathrm{~g}$ carbohydrates; $1500 \mathrm{KJ}$ ). Water was allowed ad libitum.

\section{Participants}

Nineteen young, resistance-trained individuals were recruited to this study. Sixteen participants, eight males and eight females, completed all tests and both exercise sessions ( $21 \pm 4$ years, $74 \pm 12$ $\mathrm{kg}, 1.75 \pm 11 \mathrm{~m}$; Table 2). Two participants dropped out due to muscle pains (hamstrings and 
180 groin) during testing or the exercise sessions; and one was excluded due to technical problems 181 with the test equipment.

182 The participants were familiar with heavy-load strength training and had been training upper and 183 lower body strength exercises on a weekly basis during the last year ( $\geq 2$ sessions/week). Of the 18416 participants, three were competing at a national elite level (two volleyball and one beach 185 volleyball player), one was an international-level bike trial athlete, and the remaining 12 186 participants were students at the Norwegian School of Sport Sciences (Oslo, Norway) and 187 engaged in strength training at a recreational level.

188 The study was reviewed by the Norwegian Regional Ethical Committee of Medical and Health 189 Research (2016/1120). The participants gave written informed consent to take part in the study, 190 following the Declaration of Helsinki (World Medical Association).

191 Testing and exercises

192 The familiarization session consisted of all the tests (see below) and 1-3 sets of five repetitions of 193 all the exercises (for both sessions): squat, front squat, trap bar squat, bench press, narrow bench 194 press and push-ups (Figure 1). The loads were adjusted to get close to a 5-repetition maximum 195 (RM) during the last set. For the power exercises the loads were $50 \%$ of the estimated 5RM 196 loads. In both sessions, the exercises were executed with maximal effort in the concentric phase 197 in all repetitions. In the strength-oriented session, the eccentric phase was conducted with a 198 controlled, slow movement ( $>1$ second). In contrast, in the power-oriented session the eccentric 199 phase was faster $(<1$ second $)$ in order to maximize the power output in the concentric phase. The 200 movement velocity was measured using a linear encoder (see description below).

201 On the days of the exercise sessions, the participants rated their perceived recovery status (PRS 202 scale; 0-10; (Laurent et al., 2011)) prior to a warm-up. The warm-up consisted of a 10-minute 203 easy run with increasing velocity (not more than moderate effort) preceding 2 minutes of individually selected dynamic stretching of both upper and lower body muscles. Thus, each participant followed a warm-up procedure that they were accustomed to, and the procedure was similar before each session (including the familiarization session).

207 The tests were then conducted in the following order: CMJ, SJ, 10 consecutive multiple jumps

208 (MJ), 20-meter sprint running, maximal push-up force, and power profiles and estimated 1RMs 209 in bench press and squat. Tests were performed before and immediately after the sessions, and 210 again after 24 and 48 hours. The power profile tests and 1RM estimation in the bench press and 211 squat were, however, not conducted immediately after the sessions in order to prevent additional

212 fatigue. Finally, 30 minutes after the sessions the participants rated the perceived exertion

213 (session RPE; 0-10; (Foster et al., 2001)). The participants were introduced to the ratings and

214 descriptors of both the RPE and the PRS scales at the familiarization session.

215 Tests

216 The countermovement jump (CMJ), squat jump (SJ), and multi-jump (MJ) were conducted on an 217 AMTI force platform (sampling rate: $2000 \mathrm{~Hz}$; OR6-5-1; AMTI, Watertown, MA, USA). Before 218 every test session (for each participant), offset values were acquired and the body weight of the 219 participant was measured and averaged over a $2.3 \mathrm{~s}$ period (as recommended by Street et al. 
220 (2001)). The body weight measured before each jump was confirmed against the initial weigh-in 221 value (less than 5\% discrepancy was considered valid). All force data were filtered with a low 222 pass filter (second order Butterworth bi-directional low pass filter; cut-off frequency of $120 \mathrm{~Hz}$ ).

223

224

225

226

227

228

229

230

231

232

233

234

235

236

237

238

239

240

241

242

243

244

245

246

247

248

249

250

251

252

253

254

255

256

257

All jump-tests were performed with the hands fixed on the hips (akimbo). Based on jump height, the average of each individual's two best attempts of 3-6 jumps was used for subsequent statistical analyses - except for MJ, where only one attempt was made (due to the development of fatigue). The inter-test coefficients of variation (CVs) for the jump tests are listed in Table 2.

All data collected from the AMTI force plate were analysed using a custom-made software (Matlab, The Mathworks, Inc., MA, USA; Biomekanikk AS, Oslo, Norway). From the SJ, duration, concentric peak force, peak and mean power, RFDmax, and jump height were calculated. From the CMJ, duration, eccentric time, peak and mean eccentric and concentric force, RFDmax, and jump depth (lowering of the center of mass (COM)) and jump height were calculated. From the MJ, jump height, vertical stiffness, and reactive strength index (RSI) were calculated.

Jump height was calculated as the squared take-off velocity divided by $2 g$ for all jumps (SJ, $\mathrm{CMJ}$, and MJ). Take-off velocity was calculated by the impulse-momentum method described by Linthorne (2001) and Street et al. (2001), with the impulse-integral starting from the time point when vertical force exceeded (or fell below for CMJ) 100\% of body weight and ending when force fell below $2 \mathrm{~N}$ (take-off).

The jump's phases were calculated as follows: Duration (s) of the SJ was found by backtracking force data from take-off (force $<2 \mathrm{~N}$ ) to the point where the force was $101.5 \%$ of body weight. CMJ was divided into an eccentric phase and a concentric phase (Figure 2), defined by the phase where the COM was descending and ascending, respectively. The initiation of the CMJ (eccentric phase) was found by backtracking the force data from the point of zero velocity, i.e., the deepest position of the COM, to the point where the force was $98.5 \%$ of body weight. Eccentric peak force was the highest force measured within the eccentric phase, and eccentric time was defined as the duration of the eccentric phase where the force was greater than that of the body weight (Figure 2). Peak concentric force was the highest force measured from the point of zero velocity of the COM to the point of take-off.

$* * *$ Figure $2 * * *$

The maximal rate of force development (RFD) was defined as the largest increase in force over a $5 \mathrm{~ms}$ time window during the jump (both for SJ and CMJ; Figure 2). Specifically, the RFD values $(\mathrm{N} / \mathrm{s})$ were calculated from numerical differentiation of the low-pass filtered force measurements using a 4-point method, and the derivative was averaged over $5 \mathrm{~ms}$ ( 10 samples). In the MJ test, the participants were instructed to jump ten consecutive CMJs as high as possible. The vertical stiffness was calculated as the maximal force divided by the downward displacement of the COM, while the reactive strength index (RSI) was calculated as jump-height divided by the ground contact time. All variables are presented as the average of the ten jumps.

Peer] reviewing PDF | (2020:03:46939:2:0:NEW 1 Sep 2020) 
258 Two to three maximal 20-meter sprint runs were performed on a rubberized indoor track

259 (Mondo, Conshohocken, PA, USA) with 3-4 minutes' rest between trials. The sprints were 260 measured with an electric timing system (Biomekanikk AS, Oslo, Norway) with a timing trigger 261 (single-beamed timing gate $0.6 \mathrm{~m}$ after the start line and $0.4 \mathrm{~m}$ above ground level) and dual262 beamed timing gates placed every $5 \mathrm{~m}$ along the sprint track. Participants were instructed to 263 accelerate as fast as possible from a standing start with one foot in front of the other. The inter264 test CV for the sprint test is given in Table 2.

265

266

267

268

269

270

271

272

273

274

275

276

277

278

279

280

281

282

283

284

285

286

287

288

289

290

291

292

293

294

295

296

297

298

After a specific warm-up consisting of ten push-ups with gradually increasing effort and three maximal singles, three single maximal push-ups were assessed on a force platform (sampling rate: $2000 \mathrm{~Hz}$; OR6-5-1; AMTI, Watertown, MA). One minute of rest was given between the single push-up efforts. The participants were instructed to keep their body "straight" (minimize any movement of the spine and pelvis) and to do a controlled slow eccentric phase to a position where the chest was $2-3 \mathrm{~cm}$ above the floor, and then do a push as fast as possible. The hands were allowed to leave the platform if the push-force was large enough to lift the upper body off the ground (the feet were always in contact with the ground). Hand and foot placements were standardized for each participant. If the participants failed to conduct the push as described, the attempt was discarded and repeated (this was, however, a subjective decision by the test leader). The inter-test CV for the push-up test is given in Table 2.

Bench press and squat performance were assessed using a linear encoder (Musclelab Linear Encoder; Ergotest Innovation, Langesund, Norway). The string of the encoder was attached to the bar, with the device measuring displacement (d) and time of the concentric phase $(200 \mathrm{~Hz}$ sampling rate; $0.019 \mathrm{~mm}$ resolution). The start and end of the concentric phase were detected as a $5 \mathrm{~ms}$ period of no movement $(<0.004 \mathrm{~m} / \mathrm{s})$ or immediately by a change in direction (within 5 $\mathrm{ms})$. The calculations of velocity and force from each load were based on the entire concentric phase (i.e., average/mean velocity and force; $\mathrm{v}=\mathrm{d} / \mathrm{t}$; acceleration $[\mathrm{a}]=\mathrm{v} / \mathrm{t}$, force $[\mathrm{F}]=\mathrm{mg}+\mathrm{ma}$ ).

In both the bench press and squat the participants completed sets of three maximal repetitions at four different loads, with $\sim 5$ seconds between each lift and 2-4 minutes between sets. All repetitions were conducted with maximal effort in the concentric phase. The external loads were $25,50,75$ and $90 \%$ of estimated 1RM (estimated during the familiarization session). The attempts with the highest velocity from each load were selected for further analysis. A concentric force-velocity relationship (linear regression) and a power-velocity relationship (parabolic curve) were established and peak power and 1RM were estimated (software from Ergotest Innovation, Langesund, Norway). Peak power was calculated as the apex of the parabolic power-velocity relationship. The 1RM was calculated from the intercept of the load (mg) - velocity relationship and the force $(\mathrm{mg}+\mathrm{ma})$ - velocity relationship.

For the squat, the participants were instructed to squat down to a position where the femur was parallel with the floor, in a slow, controlled manner, and then extend as rapidly and powerfully as possible. For the squat we estimated force from the system mass ( $90 \%$ of body mass and the external mass), while for the bench press, only the external mass was used. We used $90 \%$ of the body weight for the squat calculations, as suggested by the manufacturer (Ergotest Innovation, Langesund, Norway). This is very close to the $88 \%$ of body weight suggested by others using a 
299

300

301

302

303

304

305

306

307

308

309

310

311

312

313

314

315

316

317

318

319

320

321

322

323

324

325

326

327

328

329

330

331

332

333

334

335

336

337

similar linear encoder device (Cormie et al., 2007). The inter-test CVs for the bench press and squat tests are given in Table 2.

Exercise sessions

The strength-oriented session consisted of three exercises for the lower body, in the following order: squat, front squat, trap bar squat; and three exercises for the upper body, performed in the following order: normal bench press, narrow bench press and weighted push-ups (Table 1). A warm-up set of 8 repetitions at $60-80 \%$ of 5RM before each exercise preceded 5 sets of 5RM. The 5RM loads were estimated from the familiarization session for each exercise. The inter-set rest period was 3-4 minutes. The loads were adjusted between sets, if necessary. All exercises were conducted at the same tempo with a controlled slow eccentric phase and a fast as possible concentric phase. The leg exercises were performed with free weights (Eleiko, Halmstad, Sweden), while both normal and narrow bench press exercises were performed in a Smith rack (Multipower, Technogym, Cesena FC, Italy). Weighted push-ups were performed on three $30 \mathrm{~cm}$ custom-made boxes, and loads were applied by a weight-vest (1-9 kg; Reebok, Boston, Ma, US) and (if needed) weight discs (5-20 kg) placed on the participant's back, positioned over the scapulae.

The power-oriented session was conducted with loads corresponding to $50 \%$ of the external load used in the strength-oriented session. Loaded CMJ, front squat with overhead push, trap bar CMJ, normal bench press throw (Smith rack), narrow bench press throw (Smith rack), and explosive push-ups were performed with a continuous high velocity tempo in the concentric phase (Table 1).

We measured the concentric displacement for all the exercises in both sessions with a linear encoder (see above). The encoder's string was attached to the bar in all cases except for both push-up variations, where the string was attached to a light chest belt at the distal part of the sternum.

The total work was calculated by summarizing the products of repetitions, load and displacement for each set of each exercise. Only the displacement of the concentric phase was used; i.e., the distance from the vertically lowest to the vertically highest position of the bar in the squat exercise. For the lower body exercises we assumed the load to be the sum of $90 \%$ of the body weight and the external load (see above). For the front squat push, the squat part was calculated as a regular squat, but for the final overhead push only the external load was used; thus, the squat work and push work were calculated separately and then added together. For the bench press exercises, only the external load was used, while for the push-ups the weight of the upper body (measured with the force plate during testing) was added to the external load.

The first session (randomly strength or power) was used as a template for the second session for each participant. Hence, we adjusted the number of sets per exercise so that the concentric work performed in each exercise was similar between sessions. The amount of work per exercise was fine-tuned by adjusting the number of repetitions in the final set (e.g., performing only two repetitions in order to reach the required amount of work). 


\section{Statistics}

339 The data were analysed in spreadsheets that enabled adjustment of one or two predictor variables

340

341

342

343

344

345

346

347

348

349

350

351

352

353

354

355

356

357

358

359

360

361

362

363

364

365

366

367

368

369

370

371

372

373

\section{Results}

375

376

\section{Baseline valuc}

in the changes within or difference between sessions (Hopkins, 2007). The spreadsheet is fundamentally based on the T-test but gives the opportunity to adjust for baseline to control for the regression to the mean effect. All data were log-transformed, and changes are reported as percentages with their associated $95 \%$ confidence interval (CI).

The reliability of the tests was based on the familiarisation session and the two pre-tests (before each session). The coefficient of variation (CV) was calculated as described by Hopkins (2000). The smallest worthwhile change was calculated as the baseline between subjects' standard deviation (SD) multiplied by 0.2 (Hopkins, 2004).

Effects were evaluated using clinical magnitude-based inferences (MBD) (Hopkins et al., 2009;Hopkins, 2019)), a method appropriate for small samples. The magnitude of changes within and difference in mean between sessions were assessed by standardization (mean change/difference divided by baseline SD of all subjects), and the resulting standardized effect evaluated with a modification of Cohen's (1992) scale: $<0.2$, trivial; 0.2-0.6, small; 0.6-1.2, moderate; $>1.2$, large (Hopkins et al., 2009). The subjective variables (RPE and PRS) were evaluated with the following scale: $<10 \%$ trivial, $10-30 \%$ small, $30-50 \%$ moderate, $50-70 \%$ large, $70-90 \%$ very large, and 90-100\% extremely large (Hopkins, 2010). The initial RPE and PRS values were therefore factored by 10 (0-100).

To make clinical inferences about true values of effects in the population studied, the effects were expressed as probabilities of harm or benefit in relation to the smallest worthwhile change (0.2 of SD; (Hopkins et al., 2009)). A clear change within or difference between the two exercise modalities corresponds to the case of an effect that is almost certainly not harmful $(<0.5 \%$ risk of harm) and possibly beneficial ( $>25 \%$ chance of benefit). The effect is shown as the difference or change with the greatest probability, and it is shown qualitatively using the following scale: 25 $75 \%$, possibly; 75-95\%, likely; 95-99.5\%, very likely; $>99.5 \%$, most likely (Hopkins et al., 2009). In addition, $p$-values were included, and effects were considered significant at $\mathrm{p}<0.05$ if the $95 \%$ CI did not overlap zero ( $<<0.01$ with $99 \%$ CI).

Correlations between variables were obtained using Pearson's r (and 95\% CI). We restricted the correlation analyses to testing between objective and subjective variables that showed a difference between sessions, in order to minimize the risk of observing random correlations.

An order-effect is a potential risk with a crossover design (Woods et al., 1989). Hence, we tested the session-order effect by including session order as a covariate. The effects were trivial (0.0$0.5 \%$ ), so we did not further include the order effect to avoid too many covariates with the relatively low sample size (baseline value was already included).

Baseline values for the 16 participants are presented in Table 2. The differences between the two modalities at baseline were all trivial; nevertheless, baseline values were included as a covariate 
377 in all analyses of within-session changes and between session differences, and thereby controlled 378 for.

$379 * * *$ Table $2 * * *$

380 The smallest worthwhile change (SWC) and the $\mathrm{CV}$ for each variable are presented as relative 381 values (Table 2). Note that the CV was larger than the SWC for most variables (e.g., CMJ and SJ 382 RFDmax), but equal or lower for some variables (e.g., eccentric peak force).

383 Within-session changes immediately after ( 0 hours), and 24 and 48 hours after the sessions are

384

385

386

387

388

389

390

391

392

393

394

395

396

397

398

399

400

401

402

403

404

405

406

407

408

409

410

411

412

413

414

shown in Figure 3 and Table 3. Immediately after the sessions the changes were generally negative: both sessions showed small clear negative changes for most CMJ variables (height, mean power, concentric peak force, eccentric peak force; Figure 3) and SJ mean power (Table 3). The CMJ RFDmax and the subjective variables (RPE and PRS) had a clear moderate negative change after both sessions. In addition, the strength-oriented session gave clear small negative changes in CMJ depth, SJ height, SJ RFDmax, SJ duration and MJ RSI, while these were trivial after the power-oriented session (Table 3 and Figure 3).

$* * *$ Table 3 \& Figure $3 * * *$

At 24 hours similar trends emerged, with the strength-oriented session showing clear small negative effects on CMJ peak concentric force (Figure 3), SJ RFDmax, SJ duration and squat peak power; while these changes were trivial after the power-oriented session (Table 3). In addition, the strength-oriented session showed a clear moderate negative effect on CMJ eccentric time (Figure 3) and total and lower body PRS, compared to a small negative effect after the power-oriented session. In contrast, the power-oriented session gave a small possibly beneficial effect on MJ height. MJ vertical stiffness had a small increase after the strength-oriented session, while it had a clear decrease after the power-oriented session.

At 48 hours, most clear negative changes were small and only evident after the strength-oriented session (Table 3 and Figure 3). Further, CMJ RFDmax and CMJ eccentric time displayed clear moderate negative changes after the strength-oriented session (Figure 3); this was also reflected in a small increase in total duration of the CMJ $(5.3 \pm 3.5 \%) 48$ hours after the strength-oriented session. In contrast to the strength-oriented session, the power-oriented session resulted in a small possibly beneficial change in squat peak power at 48 hours (Table 3 ).

A few clear differences were observed between sessions (Figure 3 and Table 4). Compared to the power-oriented session, the strength-oriented session showed small negative effects on CMJ depth, SJ duration and MJ height immediately after the session. Moreover, the strength-oriented session was rated higher on the SRPE scale than the power-oriented session (small effect). At 24 hours, the strength-oriented session showed small clear negative effects on CMJ depth and eccentric peak force, SJ RFDmax, MJ height, squat peak power, and total, upper and lower body PRS compared to the power-oriented session. On the other hand, the strength-oriented session had a small and likely beneficial effect on MJ vertical stiffness compared to the power-oriented session.***Table $4 * * *$

Peer) reviewing PDF | (2020:03:46939:2:0:NEW 1 Sep 2020) 
415 At 48 hours, the strength-oriented session still demonstrated small and possibly to likely negative 416 effects compared to the power-oriented session for CMJ concentric and eccentric peak forces, SJ 417 RFDmax, push-up peak force and upper body PRS. The differences between sessions in CMJ 418 depth and squat peak power were partly due to improvements over baseline after the power419 oriented session.

420 To investigate the relationship between subjective and objective tests, we selected the objective 421 tests that demonstrated the greatest difference between the sessions. Hence, we correlated the 422 CMJ eccentric peak force against PRS at 24 and 48 hours after exercise; and, for the upper body, 423 push-up peak force against PRS at 24 and 48 hours after exercise (Figure 4). There were no clear

424

425

426

427

428

429

\section{Discussion}

431

432

433

434

435

436

437

438

439

440

441

442

443

444

445

446

447

448

449

450

451

452

453

***Figure $4 * * *$

\section{Previous studies} positive or systematic correlations between these variables. There was a clear negative correlation between push-up peak force and PRS at 24 hours after the power-oriented session (but not after 48 hours), indicating a counterintuitive relationship between high force (i.e., indicating a high degree of recovery) and a low degree of perceived recovery.

In this study, we aimed to compare the recovery rates after a heavy-load, strength-oriented session and a moderate-load, power-oriented session of similar concentric work. Our main findings were: 1) The strength-oriented session had, overall, the largest detrimental effects on the neuromuscular system, impairing both the eccentric and concentric phases of jumping. However, the differences in performance assessments between the sessions were generally of small or trivial magnitudes. 2) The most sensitive recovery-markers for demonstrating reduced capacity and a difference between the strength-oriented session and the power-oriented session were CMJ eccentric and concentric peak forces, SJ RFDmax and squat peak power; these variables displayed small, but likely clear differences between sessions after 24 and 48 hours of recovery. 3) In contrast to the strength-oriented session, the power-oriented session seemed to potentiate performance, as we observed small increases in MJ height after 24 hours and in squat peak power after 48 hours. 4) Finally, the strength-oriented session was perceived as more strenuous and the rate of recovery as slower compared to the power-oriented session; however, subjective and objective measurements correlated poorly at the individual level.

Small to trivial impairments of neuromuscular performance were observed after both the exercise sessions. More specifically, measures of CMJ and SJ heights and sprint times were reduced by 1$8 \%$, which are at the low end compared to previous studies ( 2-20\%; (Raastad and Hallen, 2000;Howatson et al., 2016;Raeder et al., 2016;Davies et al., 2018;Hiscock et al., 2018)). We believe that this discrepancy is because our participants were well trained, and more importantly, they were familiarized with the exercises and tests.

In line with the existing literature (Linnamo et al., 1998;Brandon et al., 2015;Howatson et al., 2016), a heavy-load strength-oriented session attenuated the neuromuscular system more than a 
454 low or moderate load power-oriented session. However, in previous studies where the exercise 455 work was controlled for, the differences between strength- and power-oriented sessions were 456 close to eliminated (McCaulley et al., 2009; Hiscock et al., 2018). Our observations confirm these 457 findings, but add some nuances to this picture, as we observed some clear differences between 458 the strength-oriented session and the power-oriented session, such as for CMJ eccentric peak 459 force. Nevertheless, the differences in recovery rates between resistance exercise sessions of 460 different modes (strength- and power-oriented) with similar exercise work must be expected to 461 be rather subtle in magnitude, but these differences may still be relevant information and 462 important for athlete monitoring and training planning. When small differences are of 463 importance, we must, however, ensure that we have adequate measurement methods.

464 Methodological issues: Reliability and fatigue sensitivity

465 To discriminate between the recovery rates of closely related exercise modalities such as 466 strength- and power-oriented sessions, highly reliable (day-to-day) tests must be applied. Based 467 on our familiarization session, and two pre-session tests, we observed very high reliability for the 468 sprint test (CV: 1\%). CMJ and SJ height and estimation of 1RMs had good reliability (CV: 3$4695 \%$ ), while peak power in the squat and bench press and MJ height had acceptable reliability 470 (CV: 9-10\%). Push-up peak force reached near acceptable reliability (CV: 11\%). Overall, the 471 reliability of tests applied in this study is in line with those of others (Raastad and Hallen, 472 2000;Hopkins et al., 2001;Byrne and Eston, 2002;Cronin et al., 2004;Cormack et al., 473 2008; Taylor et al., 2010; Gathercole et al., 2015a;Gathercole et al., 2015b). One exception among 474 our tests was the RFDmax gleaned from CMJ and SJ, which demonstrated poor reliability (CV $475>20 \%)$. Previous studies confirm a moderate to poor reliability for RFD measurements in single 476 joint knee-extension (CV = 7-17\%) (Buckthorpe et al., 2012), and for CMJ and SJ (CV = 16477 18\%) (McLellan et al., 2011; Gathercole et al., 2015a). The low reliability for RFD is probably 478 related to the complexity of the task (Maffiuletti et al., 2016), meaning that it is more difficult to 479 achieve a true maximal RFD than a maximal force. This seems to be reflected in studies showing 480 larger increases in RFD than in maximal force within a session (rehearsal) and as an effect of 481 training (Holtermann et al., 2007). That said, better reliability of RFD measures might be 482 achieved by other types of tests than the jump tests applied here; indeed, the isometric mid-thigh 483 pull test appears to be a preferable choice to assess RFD in the lower body (Haff et al., 484 2015;Hornsby et al., 2017).

485 Performance tests may also be evaluated by comparing the "smallest worthwhile change" (SWC) 486 with the typical error (Cormack et al., 2008): If the SWC is larger than the typical error, the test 487 should allegedly be able to (confidently) detect relevant and meaningful changes. Among our 488 tests, jump height and measures of force (concentric and eccentric peak force) demonstrated CVs 489 equal to or lower than the SWCs (see Table 2). Nevertheless, an evaluation of tests must be 490 applied in practice. Gathercole et al. (2015a) used the term "fatigue sensitivity", which refers to a 491 test's ability to detect impairments in neuromuscular function after exercise. As the conditions of 492 the neuromuscular system change, due to different forms of central and peripheral fatigue (Enoka 493 et al., 2011), high reliability measured in the rested state is not necessarily valid for the fatigued 494 state. In fact, tests of isolated joints, such as isokinetic knee-extension assessments, appear to 495 demonstrate larger changes than multi-joint tests, such as sprint and jump tests after different 
496 multi-joint activities (Byrne and Eston, 2002;Andersson et al., 2008; Howatson et al., 2016). To 497 this end, we suggest that tests enabling subtle changes in the movement pattern, such as sprint 498 and CMJ, may be highly reliable, but may lack fatigue sensitivity. Subtle movement/technique 499 compensations that optimize the conditions for the current state of the neuromuscular system 500 may indeed "mask" fatigue if only jump height in a CMJ is considered (Van Ingen Schenau et 501 al., 1995; Gathercole et al., 2015b).

502

503

504

505

506

507

508

509

510

511

512

513

514

515

516

517

518

519

520

521

522

523

524

525

526

527

528

529

530

531

532

533

534

535

536

As indicated above, there were trivial changes in CMJ height and peak power 24 and 48 hours after both sessions, but clear changes in CMJ eccentric time and CMJ eccentric peak force. Similar findings have recently been reported by others (Gathercole et al., 2015a). These observations indicate that the participants' ability to use the eccentric phase was impaired in the recovery phase, but some compensations in the execution of the jump apparently minimized the reductions in jump height and power production. After the strength-oriented session the reduction in eccentric peak force seemed related to a slower eccentric phase during the CMJ; i.e., increased eccentric time, since the lowering the of centre of mass was not changed. On the contrary, the participants appeared to lower their centre of mass more after the power-oriented session than at pre-test, especially at 48 hours. Future studies should investigate changes in the kinetics and kinematics (movement strategies) of a CMJ in the recovery phase compared to the rested state. However, we suggest the eccentric peak force is a more sensitive marker of fatigue and neuromuscular impairments than jump height and maximal power.

We found no clear meaningful differences between sessions or in the recovery rates between sessions for CMJ and SJ heights. This contrasts with observations by Byrne and Eston (2002), who reported that SJ height was reduced more and recovered slower than CMJ (and drop jump) height after a squat exercise session ( $10 \times 10$ repetitions at $70 \%$ of body weight). The discrepancy between findings may be related to more muscle damage in the study by Byrne and Eston (2002) than the present study - as indicated by a larger drop in performance (Paulsen et al., 2012). Moreover, studies have investigated various measures of RFD and observed that the impairment and recovery of RFD differ from maximal force (Penailillo et al., 2015;Farup et al., 2016). In our study, we extracted RFDmax from CMJ and SJ, and despite low reliability, we report small unclear and possibly clear differences between sessions at 24 and 48 hours - in accordance with previous observations (Gathercole et al., 2015a). Thus, we recognize RFDmax values from jump tests as possibly fatigue sensitive, but we warn about high day-to-day test variability (as discussed above). Moreover, the reader should be aware that sampling frequency and the methods used for (concentric/eccentric) phase identification may affect the outcomes of SJ and CMJ analyses (Owen et al., 2014;Eagles et al., 2015). Hence, comparisons across studies must be made with caution.

From the force-velocity tests in bench press and squat we calculated peak power and estimated $1 \mathrm{RM}$. The $1 \mathrm{RM}$ values had allegedly good reliability $(\mathrm{CV}<5 \%$ and $\mathrm{CV}<\mathrm{SWC})$, but contrary to the peak power, the $1 \mathrm{RM}$ values showed trivial changes after both exercise sessions. Although it has been suggested to be worth using (Jovanovic and Flanagan, 2014;Scott et al., 2016), forcevelocity estimated 1RM appears to have limited value for monitoring small changes in recovery status; i.e., estimated (or predicted) 1RM tests appear to have low fatigue sensitivity. We applied 
$537 \sim 90 \%$ of $1 \mathrm{RM}$ as the heaviest load, which may have been too low to get an accurate estimation 538 of 1RM in the squat, as observed by some (Banyard et al., 2017). For the bench press, however,

$539 \sim 90 \%$ of $1 \mathrm{RM}$ should be adequate for precise 1RM estimations - at least in an unfatigued state

540 (Jidovtseff et al., 2011;Garcia-Ramos et al., 2018a).

541 Mechanisms for neuromuscular recovery

542 Exercise-induced impairment of neuromuscular function and the following recovery phase are

543 multifaceted (Lieber and Friden, 2002;Enoka et al., 2011;Paulsen et al., 2012). However, if we

544 consider a particular exercise, such as the squat, and assume a constant range of motion (muscle

545 lengthening/strain) and a given total exercise volume (sets x repetitions), the determining factors

546 would be narrowed down to contraction/lengthening velocity and force. With the criterion of

547 maximal effort (intention to move) in the concentric phase, velocity will be high and force low

548 during light or moderate load power exercises, and vice-versa for heavy load strength exercises

549 (cf. the force-velocity relationship (Huijing, 1998)). Higher concentric forces during the heavy

550 load strength exercises will logically put more mechanical stress on the muscle tissue. However,

551 high-force concentric contractions result in minimal muscle damage and a swift recovery of

552 muscle function within 24 hours (Jones et al., 1989; Lee et al., 1999; Carson et al., 2002). Thus,

553 concentric work can probably only explain perturbations in neuromuscular function shortly after

554 exercise (i.e., minutes to a few hours, as a result of metabolic factors; (Allen et al., 2008)). This

555 led us to suggest that the eccentric phase was probably of greatest importance in the differences

556 in neuromuscular impairment and recovery rates between sessions (Paulsen et al., 2012). In other

557 words, the higher eccentric forces - simply due to higher loads - during the strength-oriented

558 session likely explain the slower recovery compared to the power-oriented session (Faulkner et

559 al., 1992;Black et al., 2007). On the other hand, the between-session differences displayed by the

560 recovery markers were generally small and trivial compared to the significant difference in loads

561 (the loads in the power session were $50 \%$ of those in the strength session). Therefore, we propose

562 that the higher eccentric velocity during the power-orientated (compared to the strength-

563 orientated session) caused a substantial mechanical stress on the muscles, despite the moderate

564 loads: Stretch-shortening cycle exercises have, indeed, been shown to induce muscle damage and

565 require days of recovery (Nicol et al., 2006). Future research should investigate this, but we

566 suggest that how the eccentric phase during power-orientated exercise is performed and the

567 utilization of the stretch-shortening cycle could have a major impact on recovery times.

\section{Lower and upper body exercise}

569 In the present study, both upper body and lower body exercises were applied. Studies exploring

570 muscle damage and recovery after eccentric exercise have reported that upper body muscles

571 sustain more damage and require longer recovery times than lower body muscles (Jamurtas et al.,

572 2005; Chen et al., 2011; Chen et al., 2019). However, recovery rates after traditional strength

573 training do not appear to be different between upper and lower body exercises, such as the bench

574 press and squat (McLester et al., 2003;Korak et al., 2015;Moran-Navarro et al., 2017). In line

575 with these studies, our data demonstrate a similar recovery rate for upper and lower body

576 exercises. Moreover, as for the lower body, the strength-oriented session seemed to induce

577 somewhat more fatigue and longer recovery times than the power-oriented session for the upper

578 body. In contrast to most studies that have investigated recovery after eccentric exercise (as cited 
579 above), we recruited well-trained individuals, which points to training status as an important 580 parameter for recovery times - rather than an inherent difference between upper or lower body 581 muscles. Nevertheless, great care should be taken when comparing recovery from different 582 exercises/sessions, because variables such as muscle strain, force and work are very difficult to 583 control for.

\section{Fatigue vs. potentiation and supercompensation}

585 Neuromuscular function can be altered through adaptation to training over weeks and months

586 (Goldspink, 1985), but the neuromuscular system is also history-dependent for shorter time 587 periods. In fact, both fatigue and potentiation are possible outcomes of muscle contractions (Sale, 588 2002). While heavy loads and large exercise volumes may induce long-lasting neuromuscular 589 fatigue (hours and days), exercises conducted with low volume and high/maximal effort can 590 result in potentiation and enhanced neuromuscular function that lasts for minutes to several hours 591 (Cook et al., 2014;Russell et al., 2016). Interestingly, in the present study the power-oriented 592 session appeared to enhance MJ height at 24 hours and squat peak power and push-up peak force 59348 hours after exercise (note that the push-up peak force at 48 hours was trivial and unclear 594 compare to baseline, but clearly different between sessions). This is in line with Tsoukos et al. 595 (2018), who observed increased CMJ height and RFDmax 24 and 48 hours after loaded jump 596 squats ( $40 \%$ of $1 \mathrm{RM} ; 5 \mathrm{x} 4$ repetitions). In contrast to squat peak power, we observed no such 597 "supercompensation" in CMJ, SJ or $20 \mathrm{~m}$ sprint (which were all back to baseline at 48 hours). 598 Notably, our participants executed a large exercise volume, about three times that of Tsoukos et 599 al. (2018), and fatigue mechanisms may have overshadowed most of the supercompensation 600 effects of power exercises. Moreover, we only followed the participants for 48 hours, which 601 means that we do not know whether the supercompensation occurred later after the strength602 oriented session (e.g. after 72 hours). As final note, potentiation effects (or supercompensation) 603 is indeed relevant for athletes, as it is common practice for "power athletes", e.g., rugby players, 604 track and field throwers and sprinters, to perform a power-oriented session close to competitions 605 ( 4-48 hours; (Russell et al., 2016); and own observations from the Norwegian Olympic Center, 606 Oslo, Norway).

\section{Objective vs subjective measures of recovery}

608 Session RPE (sRPE) for resistance exercise was reviewed by McGuigan (2004) and validated for 609 "intensity"; i.e. load in \% of 1RM, by Sweet et al. (2004). Later studies have found the sRPE to 610 be related to both volume and work rate during strength training (Scott et al., 2016; Hiscock et al., 611 2018). The present study ensured equal concentric work, but different loads - i.e., the power612 oriented session was performed with $50 \%$ of the loads used in the strength-oriented session.

613 Nevertheless, because the power-oriented session lasted $\sim 12 \%$ ( 13 minutes) longer than the 614 strength-oriented session, the work rate was highest during the strength-oriented session. As the 615 difference in loads ( $\%$ of $1 \mathrm{RM}$ ) between sessions was much larger than the difference in work 616 rate, we suggest that the higher loads (\% of 1RM) were the dominant factor influencing the sRPE 617 scores (although we acknowledge that this cannot be ascertained with the present study design).

618 Notably, it has been proposed that exercise intensity/load (\% of 1RM) influences RPE scores via 619 a positive relationship with the central motor control discharge (Gearhart et al., 2002), cf. the 620 "corollary discharge model" (Pageaux, 2016). However, our participants in both sessions were 
622

623

624

625

626

627

628

629

630

631

632

633

634

635

636

637

638

639

640

641

642

643

644

645

646

647

648

649

650

651

652

653

654

655

656

657

658

659

660

661

662

663
621 strongly encouraged to execute every repetition with the intention to move as fast as possible in
622 the concentric phase. Indeed, both the motor-related cortical potentials (MRCP; (Slobounov et al., 2004)) and the electromyographic (EMG) amplitude seem independent of load (\% of 1RM) if the intention to move is maximal - at least for lower body exercises (Bosco et al., 1982; Hakkinen et al., 1986;Kawamori and Haff, 2004;McBride et al., 2010). If we assume that our participants moved maximally in all repetitions, the corollary discharge model seems unable to explain a higher sRPE after the strength-oriented session than the power-oriented session. Consequently, we suggest that the sRPE scores in the present study were influenced by afferent feedback from the muscles; supporting a "combined model" (Pageaux, 2016). The afferent feedback may be a combination of different sensors including tendon organs ("force sensors") and nociceptor receptors responding to metabolic perturbations. Metabolic perturbations, such as elevated extracellular levels of adenosine, lactate and protons (Allen et al., 2008), stimulate capsaicin fibres (A $\delta$ and C-nerves; (Pollak et al., 2014)); and accordingly, muscular fatigue may be an important underlying mechanism behind the RPE scores (Hardee et al., 2012; Vasquez et al., 2013). When working at maximal intensity, fatigue will start to develop within seconds (Allen et al., 2008), and probably to a larger degree during the strength-oriented session than the power-oriented session due to more time under tension (i.e., a longer acceleration phase during the lifts and/or less deacceleration). We cannot exclude the possibility that the participants used elastic energy storage and release (the stretch shortening cycle) during the power-oriented session, and thereby had better energy economy during the power-oriented session than the strength-oriented session (Bosco et al., 1982). Higher energy expenditure and more fatigue in combination with the heavier loads could explain the higher sRPE after the strength-oriented session than the power-oriented session. Finally, it is noteworthy that the "contents"/definition of the RPE concept, i.e., effort vs. force, pain and discomfort, and the mechanisms behind RPE, are debatable (Pageaux, 2016). Moreover, the timing of reporting RPE, e.g. during or immediately after an exercise vs. 30 minutes after a session (i.e., sRPE), may be important for the decisive mechanisms of the RPE scores; thus, more scientific work is needed to better understand the use of sRPE in relation to different modes of resistance exercise.

While sRPE scores are collected after a session, PRS is obtained before an exercise session. PRS is supposed to give an evaluation of the athletes' readiness and performance status in the upcoming session (Laurent et al., 2011). In the present study, recovery status 24 and 48 hours after the strength-oriented session were reported lower compared to the power-oriented session. Indeed, as for sRPE, PRS pointed in the same direction as the objective tests. However, no consistent correlations were found between the PRS and objective variables, such as CMJ eccentric peak force and push-up peak force. Interestingly, the state of recovery was perceived as incomplete both 24 and 48 hours after the power-oriented session although performance was back to baseline, or even above (squat peak power and MJ). Recent studies support a partly dissociated time course between objective and subjective recovery status - for both upper and lower body muscles - indicating a slower recovery when assessed subjectively (Zourdos et al., 2016;Ferreira et al., 2017a;Ferreira et al., 2017b;Marshall et al., 2018). In summary, this advocates for caution in interpreting subjective and objective measures of recovery. In our case (and perhaps most cases), it is conceivable that neither the subjective nor the objective measures revealed the true recovery status. On the objective side we merely measured some properties of

Peer] reviewing PDF | (2020:03:46939:2:0:NEW 1 Sep 2020) 
664 the neuromuscular system, leaving the possibility that unassessed properties were not recovered. 665 Interstingly, Zourdos et al. (2016) observed a difference in the PRS when assessed before and 666 after warm-up (higher PRS after warm-up). We assessed PRS only before warm-up, leaving the 667 possibility for higher coherence between objective measurements and PRS if evaluated after 668 warm-up.

\section{Limitations}

670 The present study has limitations. First, we applied a series of tests and we cannot exclude the 671 possibility that the tests themselves induced fatigue that affected the results; e.g., reduced the test 672 reliability. Moreover, we had no control trial in which the participants simply conducted the four 673 test-sessions without participating in an exercise session (see Figure 1). Consequently, we must 674 be careful interpreting the changes in relation to time after each session (within-session changes); 675 it is possible that the recovery was prolonged due to all the tests.

676 Second, we calculated the work done based on concentric work; thus, we excluded eccentric 677 work, and we cannot rule out that some differences between sessions could have been explained 678 by this fact.

679 Third, each participant completed two sessions. Due to the repeated bout effect, a faster recovery 680 must be expected after the second session (McHugh, 2003). Moreover, since the loads (in \% of 681 1RM) were higher in the strength-oriented session, the adaptative processes may have been 682 better stimulated after the strength- than the power-oriented session (i.e., strengthening of the 683 myofiber cytoskeleton (Paulsen et al., 2009)). If true, this may have created a bias toward faster 684 recovery after the power-oriented session. Furthermore, the time between sessions (the washout 685 period) varied between the participants (1-4 weeks), which means that their training status may 686 have changed slightly. This effect does appear small as the pre-values before each session were 687 very similar, with low to moderate CV for all variables (Table 2). To this end, the order of 688 sessions was randomized, and the impact of session-order was trivial when controlled for.

689

690

691

692

693

694

695

696

697

698

699

700

701

702

703 Additionally, we recruited both females and males. The participants had different training backgrounds and we did not control their training in the washout period (except during the 48 hours before each session). We did not fully control the diets of the participants. We acknowledge that these factors may have induced biases and variability in our results.

Fourth, we did not include tests that allowed us to distinguish between central and peripheral fatigue, nor did we measure systemic markers of recovery (such as creatine kinase, testosterone and cortisol; (Buckthorpe et al., 2014;Hiscock et al., 2018; Tsoukos et al., 2018)). This could have given us valuable information about the subtle impairments of neuromuscular performance and recovery between sessions.

Fifth, we acknowledge that the definition of the different variables gleaned from the SJ and CMJ tests are open for debate. Particularly, we want to make the reader aware of the fact that CMJ peak eccentric and concentric force are reached within a very narrow time window in the lowest position of the jump. Thus, collecting only the force in the lowest squat position could yield the necessary information, with the advantage that the point/position is clearly defined (easily reproducible). 
704 Finally, one should be careful about extrapolating the results of this study to other training 705 interventions/programs due the many combinations/possibilities within a strength/power training

706 program that may be important in the recovery process, such as exercises, load, volume, work

707 and interest-rest periods.

\section{Practical applications}

709 Knowledge of recovery from exercise sessions is needed to make qualified assumptions when

710 designing training programs, particularly for elite athletes who must handle large training

711 volumes and avoid overtraining. The present and previous studies have shown that to monitor

712 recovery one must consider a combination of tests and be aware of the error of measurements. In

713 our study, the eccentric peak force during a CMJ and the peak power calculated from a squat

714 force-velocity test were the variables that seemingly best differentiated between a strength-

715 oriented session and a power-oriented session. Further research is warranted to see whether these

716 tests are valid for other modes of resistance exercise and with participants of different

717 performance levels (training status).

718 In our hands, RFD from CMJ and SJ seem to have too large a day-to-day variability to be

719 recommended for monitoring recovery. Improved standardizations and instructions to the athlete

720 may be worth exploring. Similarly, for the upper body our applied tests were not fully

721 satisfactory in terms of reliability and fatigue sensitivity, implying that more work is needed.

722 The power-oriented session tended to improve performance in certain tests at 24 and/or 48 hours

723 after exercise. Potentiation or a fast supercompensation from power-oriented sessions is highly

724 relevant for athletes preparing for competitions.

725 Objective and subjective tests of recovery may not correlate. Consequently, both test modalities

726 should be used and interpreted together to ensure a holistic approach (Kiely, 2012). Because the

727 recovery process is so complex, it is important to acknowledge that there is much we do not

728 know or understand; thus, relying on only objective or only subjective measurers could prove

729 inadequate for most athletes.

730 It appears that the best tests for assessing recovery will differ significantly according to the 731 exercises that have been conducted. Consequently, we cannot expect a "gold standard" test 732 battery. Rather, we need to use a selected number of tests for each specific athlete or group of 733 athletes, and a combination of subjective and objective tests appears advisable.

\section{Conclusion}

736 We hypothesized that a heavy-load, strength-oriented exercise session would require a longer 737 recovery period than a moderate-load, power-oriented session with equal concentric work. Our 738 hypothesis was confirmed as the power-oriented session required less than 48 hours of recovery, 739 while the strength-oriented session required more than 48 hours. The strength-oriented session 740 induced an overall larger detrimental effect on the neuromuscular system than the power-

741 oriented session at all time points $(0,24$ and 48 hours), reducing both power and strength 742 properties. However, differences in the performance assessments between the exercise sessions 
743 were generally small or trivial. The apparently best markers for detecting differences between the

744 strength-oriented session and power-oriented session were the CMJ derivate eccentric peak force

745 and squat peak power. Considering the good reliability (lower than the SWC), the CMJ eccentric

746 peak force seemed to be the most sensitive parameter. For the upper body, the push-up peak

747 force seemed more sensitive as a recovery marker than bench press peak power and 1RM, but

748 the push-up had only acceptable reliability. In contrast to the strength-oriented session, the

749 power-oriented session seemed to potentiate multi-jump performance and squat peak power.

750 Furthermore, the strength-oriented session was experienced as more strenuous (higher sRPE) and

751 more recovery was perceived to be required (lower PRS) compared to the power-oriented

752 session, which were in accordance with our secondary hypothesis. However, our third hypothesis

753 was falsified as the subjective measurements correlated poorly (inconsistently) with the objective

754 measurements; indicating the need for both objective and subjective measurements in practice.

\section{Acknowledgements}

756 We would like to thank all the participants for their hard work, the staff at the Norwegian

757 Olympic Sports Center for good help facilitate the testing and training, and Biomekanikk AS for 758 the help with processing force plate data.

759

\section{Data availability statement}

761 The raw data set is available.

762

763

764

765

766

767

\section{Author contributions statement}

$\mathrm{CH}, \mathrm{DSO}$, LH and GP conceived and designed the study. CH, MM, FS, LH, DSO, and GP carried out the study and collected the data. CH, DSO, PS, and GP performed statistical analyses and interpreted the data. CH, PS and GP wrote the manuscript. All authors read and approved the final manuscript.

768

\section{Conflicts of interest}

Author Daniela Schäfer Olstad was employed by the company Polar Electro Oy. Of note, the

771 present study does not contain any data collected by Polar Electro Oy equipment/devices. The

772 remaining authors declare that the research was conducted in the absence of any commercial or financial relationships that could be construed as a potential conflict of interest. 


\section{References}

776

777

778

779

780

781

782

783

784

785

786

787

788

789

790

791

792

793

794

795

796

797

798

799

800

801

802

803

804

805

806

807

808

809

810

811

812

813

814

815

816

817

818

819

820

821

822

823
Ahtiainen, J.P., Pakarinen, A., Kraemer, W.J., and Hakkinen, K. (2003). Acute hormonal and neuromuscular responses and recovery to forced vs maximum repetitions multiple resistance exercises. Int J Sports Med 24, 410-418.

Ahtiainen, J.P., Pakarinen, A., Kraemer, W.J., and Hakkinen, K. (2004). Acute hormonal responses to heavy resistance exercise in strength athletes versus nonathletes. Can $J$ Appl Physiol 29, 527-543.

Allen, D.G., Lamb, G.D., and Westerblad, H. (2008). Skeletal muscle fatigue: cellular mechanisms. Physiol Rev 88, 287-332.

Andersson, H., Raastad, T., Nilsson, J., Paulsen, G., Garthe, I., and Kadi, F. (2008). Neuromuscular fatigue and recovery in elite female soccer: effects of active recovery. Med. Sci. Sports Exerc 40, 372-380.

Banyard, H.G., Nosaka, K., and Haff, G.G. (2017). Reliability and Validity of the Load-Velocity Relationship to Predict the 1RM Back Squat. J Strength Cond Res 31, 1897-1904.

Banyard, H.G., Nosaka, K., Vernon, A.D., and Haff, G.G. (2018). The Reliability of Individualized Load-Velocity Profiles. Int J Sports Physiol Perform 13, 763-769.

Bishop, P.A., Jones, E., and Woods, A.K. (2008). Recovery from training: a brief review:. J Strength Cond. Res 22, 1015-1024.

Black, C.D., Elder, C.P., Gorgey, A., and Dudley, G.A. (2007). High Specific Torque is Related to Lengthening Contraction Induced Skeletal Muscle Injury. J Appl Physiol.

Borg, G. (1970). Perceived exertion as an indicator of somatic stress. Scand J Rehabil Med 2, 92-98.

Bosco, C., Viitasalo, J.T., Komi, P.V., and Luhtanen, P. (1982). Combined effect of elastic energy and myoelectrical potentiation during stretch-shortening cycle exercise. Acta Physiol Scand 114, 557-565.

Brandon, R., Howatson, G., Strachan, F., and Hunter, A.M. (2015). Neuromuscular response differences to power vs strength back squat exercise in elite athletes. Scand J Med Sci Sports 25, 630-639.

Buckthorpe, M., Pain, M.T., and Folland, J.P. (2014). Central fatigue contributes to the greater reductions in explosive than maximal strength with high-intensity fatigue. Exp Physiol 99, 964-973.

Buckthorpe, M.W., Hannah, R., Pain, T.G., and Folland, J.P. (2012). Reliability of neuromuscular measurements during explosive isometric contractions, with special reference to electromyography normalization techniques. Muscle Nerve 46, 566-576.

Byrne, C., and Eston, R. (2002). The effect of exercise-induced muscle damage on isometric and dynamic knee extensor strength and vertical jump performance. J. Sports Sci 20, 417-425.

Carson, R.G., Riek, S., and Shahbazpour, N. (2002). Central and peripheral mediation of human force sensation following eccentric or concentric contractions. J. Physiol 539, 913-925.

Chatzinikolaou, A., Fatouros, I.G., Gourgoulis, V., Avloniti, A., Jamurtas, A.Z., Nikolaidis, M.G., Douroudos, I., Michailidis, Y., Beneka, A., Malliou, P., Tofas, T., Georgiadis, I., Mandalidis, D., and Taxildaris, K. (2010). Time course of changes in performance and inflammatory responses after acute plyometric exercise. J Strength Cond Res 24, 13891398.

Chen, T.C., Lin, K.Y., Chen, H.L., Lin, M.J., and Nosaka, K. (2011). Comparison in eccentric exercise-induced muscle damage among four limb muscles. Eur J Appl Physiol 111, 211-223.

Peer] reviewing PDF | (2020:03:46939:2:0:NEW 1 Sep 2020) 
824

825

826

827

828

829

830

831

832

833

834

835

836

837

838

839

840

841

842

843

844

845

846

847

848

849

850

851

852

853

854

855

856

857

858

859

860

861

862

863

864

865

866

867

868

869

870

871

872

873
Chen, T.C., Yang, T.J., Huang, M.J., Wang, H.S., Tseng, K.W., Chen, H.L., and Nosaka, K. (2019). Damage and the repeated bout effect of arm, leg, and trunk muscles induced by eccentric resistance exercises. Scand J Med Sci Sports 29, 725-735.

Cook, C.J., Kilduff, L.P., Crewther, B.T., Beaven, M., and West, D.J. (2014). Morning based strength training improves afternoon physical performance in rugby union players. $J$ Sci Med Sport 17, 317-321.

Cormack, S.J., Newton, R.U., Mcguigan, M.R., and Doyle, T.L. (2008). Reliability of measures obtained during single and repeated countermovement jumps. Int J Sports Physiol Perform 3, 131-144.

Cormie, P., Mcbride, J.M., and Mccaulley, G.O. (2007). The influence of body mass on calculation of power during lower-body resistance exercises. J Strength Cond Res 21, 1042-1049.

Cronin, J.B., Hing, R.D., and Mcnair, P.J. (2004). Reliability and validity of a linear position transducer for measuring jump performance. J Strength Cond Res 18, 590-593.

Cunanan, A.J., Deweese, B.H., Wagle, J.P., Carroll, K.M., Sausaman, R., Hornsby, W.G., 3rd, Haff, G.G., Triplett, N.T., Pierce, K.C., and Stone, M.H. (2018). The General Adaptation Syndrome: A Foundation for the Concept of Periodization. Sports Med 48, 787-797.

Davies, R.W., Carson, B.P., and Jakeman, P.M. (2018). Sex Differences in the Temporal Recovery of Neuromuscular Function Following Resistance Training in Resistance Trained Men and Women 18 to 35 Years. Front Physiol 9, 1480.

Eagles, A.N., Sayers, M.G.L., Bousson, M., and Lovell, D.I. (2015). Current Methodologies and Implications of Phase Identification of the Vertical Jump: A Systematic Review and Metaanalysis. Sports Med 45, 1311-1323.

Enoka, R.M., Baudry, S., Rudroff, T., Farina, D., Klass, M., and Duchateau, J. (2011). Unraveling the neurophysiology of muscle fatigue. J Electromyogr Kinesiol 21, 208-219.

Farup, J., Rahbek, S.K., Bjerre, J., De, P.F., and Vissing, K. (2016). Associated decrements in rate of force development and neural drive after maximal eccentric exercise. Scand $J$ Med Sci Sports 26, 498-506.

Faulkner, J.A., Opiteck, J.A., and Brooks, S.V. (1992). Injury to skeletal muscle during altitude training: induction and prevention. Int J Sports Med 13 Suppl 1, S160-S162.

Ferreira, D.V., Ferreira-Junior, J.B., Soares, S.R., Cadore, E.L., Izquierdo, M., Brown, L.E., and Bottaro, M. (2017a). Chest Press Exercises With Different Stability Requirements Result in Similar Muscle Damage Recovery in Resistance-Trained Men. J Strength Cond Res 31, 71-79.

Ferreira, D.V., Gentil, P., Ferreira-Junior, J.B., Soares, S.R.S., Brown, L.E., and Bottaro, M. (2017b). Dissociated time course between peak torque and total work recovery following bench press training in resistance trained men. Physiol Behav 179, 143-147.

Foster, C., Florhaug, J.A., Franklin, J., Gottschall, L., Hrovatin, L.A., Parker, S., Doleshal, P., and Dodge, C. (2001). A new approach to monitoring exercise training. J Strength Cond Res 15, 109-115.

Foster, C., Rodriguez-Marroyo, J.A., and De Koning, J.J. (2017). Monitoring Training Loads: The Past, the Present, and the Future. Int J Sports Physiol Perform 12, S22-S28.

Garcia-Ramos, A., Haff, G.G., Pestana-Melero, F.L., Perez-Castilla, A., Rojas, F.J., BalsalobreFernandez, C., and Jaric, S. (2018a). Feasibility of the 2-Point Method for Determining the 1-Repetition Maximum in the Bench Press Exercise. Int J Sports Physiol Perform 13, 474-481.

Garcia-Ramos, A., Pestana-Melero, F.L., Perez-Castilla, A., Rojas, F.J., and Gregory Haff, G. (2018b). Mean Velocity vs. Mean Propulsive Velocity vs. Peak Velocity: Which Variable Determines Bench Press Relative Load With Higher Reliability? J Strength Cond Res 32, 1273-1279.

Peer] reviewing PDF | (2020:03:46939:2:0:NEW 1 Sep 2020) 
874

875

876

877

878

879

880

881

882

883

884

885

886

887

888

889

890

891

892

893

894

895

896

897

898

899

900

901

902

903

904

905

906

907

908

909

910

911

912

913

914

915

916

917

918

919

920

921

922

923

Gathercole, R., Sporer, B., Stellingwerff, T., and Sleivert, G. (2015a). Alternative countermovement-jump analysis to quantify acute neuromuscular fatigue. Int J Sports Physiol Perform 10, 84-92.

Gathercole, R.J., Sporer, B.C., Stellingwerff, T., and Sleivert, G.G. (2015b). Comparison of the Capacity of Different Jump and Sprint Field Tests to Detect Neuromuscular Fatigue. $J$ Strength Cond Res 29, 2522-2531.

Gearhart, R.F., Jr., Goss, F.L., Lagally, K.M., Jakicic, J.M., Gallagher, J., Gallagher, K.I., and Robertson, R.J. (2002). Ratings of perceived exertion in active muscle during highintensity and low-intensity resistance exercise. J Strength Cond Res 16, 87-91.

Goldspink, G. (1985). Malleability of the motor system: a comparative approach. J Exp Biol 115, 375-391.

Haff, G.G., Ruben, R.P., Lider, J., Twine, C., and Cormie, P. (2015). A comparison of methods for determining the rate of force development during isometric midthigh clean pulls. $J$ Strength Cond Res 29, 386-395.

Hakkinen, K., Komi, P.V., and Kauhanen, H. (1986). Electromyographic and force production characteristics of leg extensor muscles of elite weight lifters during isometric, concentric, and various stretch-shortening cycle exercises. Int. J Sports Med 7, 144-151.

Hardee, J.P., Lawrence, M.M., Utter, A.C., Triplett, N.T., Zwetsloot, K.A., and Mcbride, J.M. (2012). Effect of inter-repetition rest on ratings of perceived exertion during multiple sets of the power clean. Eur J Appl Physiol 112, 3141-3147.

Hiscock, D.J., Dawson, B., Clarke, M., and Peeling, P. (2018). Can changes in resistance exercise workload influence internal load, countermovement jump performance and the endocrine response? J Sports Sci 36, 191-197.

Holtermann, A., Roeleveld, K., Vereijken, B., and Ettema, G. (2007). The effect of rate of force development on maximal force production: acute and training-related aspects. Eur $J$ Appl Physiol 99, 605-613.

Hopkins, W.G. (2000). Measures of reliability in sports medicine and science. Sports Med 30, 115.

Hopkins, W.G. (2004). How to interpret changes in an athletic performance test. Sportscience 8, $1-7$.

Hopkins, W.G. (2007). Spreadsheets for analysis of controlled trials, crossovers and time series. Sportscience 21, 1-4.

Hopkins, W.G. (2010). Linear models and effect magnitudes for research, clinical and practical applications. Sportscience 14, 49-58.

Hopkins, W.G. (2019). Magnitude-Based Decisions: Rebranding. Sportscience 23, i-iii.

Hopkins, W.G., Marshall, S.W., Batterham, A.M., and Hanin, J. (2009). Progressive statistics for studies in sports medicine and exercise science. Med Sci Sports Exerc 41, 3-13.

Hopkins, W.G., Schabort, E.J., and Hawley, J.A. (2001). Reliability of power in physical performance tests. Sports Med 31, 211-234.

Hornsby, W.G., Gentles, J.A., Macdonald, C.J., Mizuguchi, S., Ramsey, M.W., and Stone, M.H. (2017). Maximum Strength, Rate of Force Development, Jump Height, and Peak Power Alterations in Weightlifters across Five Months of Training. Sports (Basel) 5.

Howatson, G., Brandon, R., and Hunter, A.M. (2016). The Response to and Recovery From Maximum-Strength and -Power Training in Elite Track and Field Athletes. Int J Sports Physiol Perform 11, 356-362.

Huijing, P.A. (1998). Muscle, the motor of movement: properties in function, experiment and modelling. J Electromyogr Kinesiol 8, 61-77.

Jamurtas, A.Z., Theocharis, V., Tofas, T., Tsiokanos, A., Yfanti, C., Paschalis, V., Koutedakis, Y., and Nosaka, K. (2005). Comparison between leg and arm eccentric exercises of the same relative intensity on indices of muscle damage. Eur J Appl Physiol 95, 179-185.

Peer] reviewing PDF | (2020:03:46939:2:0:NEW 1 Sep 2020) 
924

925

926

927

928

929

930

931

932

933

934

935

936

937

938

939

940

941

942

943

944

945

946

947

948

949

950

951

952

953

954

955

956

957

958

959

960

961

962

963

964

965

966

967

968

969

970

971

972

973
Jidovtseff, B., Harris, N.K., Crielaard, J.M., and Cronin, J.B. (2011). Using the load-velocity relationship for 1RM prediction. J Strength Cond Res 25, 267-270.

Jones, D.A., Newham, D.J., and Torgan, C. (1989). Mechanical influences on long-lasting human muscle fatigue and delayed- onset pain. J. Physiol 412, 415-427.

Jovanovic, M., and Flanagan, E.P. (2014). Researched applications of velocity based strength training. J Aust Strength Cond 22.

Kawamori, N., and Haff, G.G. (2004). The optimal training load for the development of muscular power. J Strength Cond Res 18, 675-684.

Kellmann, M., Bertollo, M., Bosquet, L., Brink, M., Coutts, A.J., Duffield, R., Erlacher, D., Halson, S.L., Hecksteden, A., Heidari, J., Kallus, K.W., Meeusen, R., Mujika, I., Robazza, C., Skorski, S., Venter, R., and Beckmann, J. (2018). Recovery and Performance in Sport: Consensus Statement. Int J Sports Physiol Perform 13, 240-245.

Kiely, J. (2012). Periodization paradigms in the 21st century: evidence-led or tradition-driven? Int J Sports Physiol Perform 7, 242-250.

Korak, J.A., Green, J.M., and O'neal, E.K. (2015). Resistance training recovery: Considerations for single vs. multijoint movements and upper vs. lower body muscles. International Journal of Exercise Science 8, 12.

Laurent, C.M., Green, J.M., Bishop, P.A., Sjokvist, J., Schumacker, R.E., Richardson, M.T., and Curtner-Smith, M. (2011). A practical approach to monitoring recovery: development of a perceived recovery status scale. J Strength Cond Res 25, 620-628.

Lee, H.D., Suter, E., and Herzog, W. (1999). Force depression in human quadriceps femoris following voluntary shortening contractions. J. Appl. Physiol 87, 1651-1655.

Lieber, R.L., and Friden, J. (2002). Morphologic and mechanical basis of delayed-onset muscle soreness. J Am Acad Orthop Surg 10, 67-73.

Linnamo, V., Hakkinen, K., and Komi, P.V. (1998). Neuromuscular fatigue and recovery in maximal compared to explosive strength loading. Eur. J Appl. Physiol Occup. Physiol 77, 176-181.

Linthorne, N.P. (2001). Analysis of stading vertical jump using a force platform. Am J Phys 69, 1198-1204.

Maffiuletti, N.A., Aagaard, P., Blazevich, A.J., Folland, J., Tillin, N., and Duchateau, J. (2016). Rate of force development: physiological and methodological considerations. Eur J Appl Physiol 116, 1091-1116.

Marshall, P.W.M., Cross, R., and Haynes, M. (2018). The fatigue of a full body resistance exercise session in trained men. J Sci Med Sport 21, 422-426.

Mcbride, J.M., Larkin, T.R., Dayne, A.M., Haines, T.L., and Kirby, T.J. (2010). Effect of absolute and relative loading on muscle activity during stable and unstable squatting. Int $J$ Sports Physiol Perform 5, 177-183.

Mccaulley, G.O., Mcbride, J.M., Cormie, P., Hudson, M.B., Nuzzo, J.L., Quindry, J.C., and Travis Triplett, N. (2009). Acute hormonal and neuromuscular responses to hypertrophy, strength and power type resistance exercise. Eur J Appl Physiol 105, 695-704.

Mcguigan, M.R.F., C. (2004). A new approach to monitoring resistance training. Strength and Conditioning Journal 26, 6.

Mchugh, M.P. (2003). Recent advances in the understanding of the repeated bout effect: the protective effect against muscle damage from a single bout of eccentric exercise. Scand. J. Med. Sci. Sports 13, 88-97.

Mclellan, C.P., Lovell, D.I., and Gass, G.C. (2011). The role of rate of force development on vertical jump performance. J Strength Cond Res 25, 379-385.

Mclester, J.R., Bishop, P.A., Smith, J., Wyers, L., Dale, B., Kozusko, J., Richardson, M., Nevett, M.E., and Lomax, R. (2003). A series of studies--a practical protocol for testing muscular endurance recovery. J Strength Cond Res 17, 259-273.

Peer] reviewing PDF | (2020:03:46939:2:0:NEW 1 Sep 2020) 
974

975

976

977

978

979

980

981

982

983

984

985

986

987

988

989

990

991

992

993

994

995

996

997

998

999

1000

1001

1002

1003

1004

1005

1006

1007

1008

1009

1010

1011

1012

1013

1014

1015

1016

1017

1018

1019

1020

1021

1022

Moran-Navarro, R., Perez, C.E., Mora-Rodriguez, R., De La Cruz-Sanchez, E., GonzalezBadillo, J.J., Sanchez-Medina, L., and Pallares, J.G. (2017). Time course of recovery following resistance training leading or not to failure. Eur J Appl Physiol 117, 2387-2399.

Newton, R.U., and Kraemer, W.J. (1994). Developing explosive muscular power: Implications of mixed methods training strategy. Strength Cond J, 20-31.

Nicol, C., Avela, J., and Komi, P.V. (2006). The stretch-shortening cycle : a model to study naturally occurring neuromuscular fatigue. Sports Med 36, 977-999.

Owen, N.J., Watkins, J., Kilduff, L.P., Bevan, H.R., and Bennett, M.A. (2014). Development of a criterion method to determine peak mechanical power output in a countermovement jump. J Strength Cond Res 28, 1552-1558.

Pageaux, B. (2016). Perception of effort in Exercise Science: Definition, measurement and perspectives. Eur J Sport Sci 16, 885-894.

Paulsen, G., Lauritzen, F., Bayer, M.L., Kalhovde, J.M., Ugelstad, I., Owe, S.G., Hallen, J., Bergersen, L.H., and Raastad, T. (2009). Subcellular movement and expression of HSP27, alphaB-crystallin, and HSP70 after two bouts of eccentric exercise in humans. $J$ Appl Physiol 107, 570-582.

Paulsen, G., Mikkelsen, U.R., Raastad, T., and Peake, J.M. (2012). Leucocytes, cytokines and satellite cells: what role do they play in muscle damage and regeneration following eccentric exercise? Exerc Immunol Rev 18, 42-97.

Penailillo, L., Blazevich, A., Numazawa, H., and Nosaka, K. (2015). Rate of force development as a measure of muscle damage. Scand J Med Sci Sports 25, 417-427.

Pollak, K.A., Swenson, J.D., Vanhaitsma, T.A., Hughen, R.W., Jo, D., White, A.T., Light, K.C., Schweinhardt, P., Amann, M., and Light, A.R. (2014). Exogenously applied muscle metabolites synergistically evoke sensations of muscle fatigue and pain in human subjects. Exp. Physiol 99, 368-380.

Raastad, T., and Hallen, J. (2000). Recovery of skeletal muscle contractility after high- and moderate-intensity strength exercise. Eur J Appl Physiol 82, 206-214.

Raeder, C., Wiewelhove, T., Westphal-Martinez, M.P., Fernandez-Fernandez, J., De Paula Simola, R.A., Kellmann, M., Meyer, T., Pfeiffer, M., and Ferrauti, A. (2016). Neuromuscular Fatigue and Physiological Responses After Five Dynamic Squat Exercise Protocols. J Strength Cond Res 30, 953-965.

Russell, M., King, A., Bracken, R.M., Cook, C.J., Giroud, T., and Kilduff, L.P. (2016). A Comparison of Different Modes of Morning Priming Exercise on Afternoon Performance. Int J Sports Physiol Perform 11, 763-767.

Sale, D.G. (2002). Postactivation potentiation: role in human performance. Exerc Sport Sci Rev 30, 138-143.

Scott, B.R., Duthie, G.M., Thornton, H.R., and Dascombe, B.J. (2016). Training Monitoring for Resistance Exercise: Theory and Applications. Sports Med 46, 687-698.

Sikorski, E.M., Wilson, J.M., Lowery, R.P., Joy, J.M., Laurent, C.M., Wilson, S.M., Hesson, D., Naimo, M.A., Averbuch, B., and Gilchrist, P. (2013). Changes in perceived recovery status scale following high-volume muscle damaging resistance exercise. J Strength Cond Res 27, 2079-2085.

Slobounov, S., Hallett, M., and Newell, K.M. (2004). Perceived effort in force production as reflected in motor-related cortical potentials. Clin Neurophysiol 115, 2391-2402.

Street, G., Mcmillan, S., Board, W., Rasmussen, M., and Heneghan, J.M. (2001). Sources of error in determining countermovement jump height with the impulse method. $J$ Appl Biomech 17, 43-54.

Suchomel, T., Comfort, P., and Lake, J.P. (2017). Enhancing the force-velocity profile of athletes using weightlifting derivatives. Strength Cond J 39, 10-20.

Peer] reviewing PDF | (2020:03:46939:2:0:NEW 1 Sep 2020) 
1023

1024

1025

1026

1027

1028

1029

1030

1031

1032

1033

1034

1035

1036

1037

1038

1039

1040

1041

1042

1043

1044

1045

1046

1047

1048
Sweet, T.W., Foster, C., Mcguigan, M.R., and Brice, G. (2004). Quantitation of resistance training using the session rating of perceived exertion method. J Strength Cond Res 18, 796-802.

Taylor, K.L., Cronin, J., Gill, N.D., Chapman, D.W., and Sheppard, J. (2010). Sources of variability in iso-inertial jump assessments. Int J Sports Physiol Perform 5, 546-558.

Tsoukos, A., Veligekas, P., Brown, L.E., Terzis, G., and Bogdanis, G.C. (2018). Delayed Effects of a Low-Volume, Power-Type Resistance Exercise Session on Explosive Performance. $J$ Strength Cond Res 32, 643-650.

Urbaniak, G.C., and Plous, S. (2013). Research Randomizer (Version 4.0) [Computer software]. http://www.randomizer.org/. [Online]. [Accessed].

Van Ingen Schenau, G.J., Van Soest, A.J., Gabreels, F.J., and Horstin, M.W. (1995). The control of multi-joint movements relies on detailed internal representations. Hum Mov Sci 14, 511-538.

Vasquez, L.M., Mcbride, J.M., Paul, J.A., Alley, J.R., Carson, L.T., and Goodman, C.L. (2013). Effect of resistance exercise performed to volitional failure on ratings of perceived exertion. Percept Mot Skills 117, 881-891.

Vincent, H.K., and Vincent, K.R. (1997). The effect of training status on the serum creatine kinase response, soreness and muscle function following resistance exercise. Int $J$ Sports Med 18, 431-437.

Woods, J.R., Williams, J.G., and Tavel, M. (1989). The two-period crossover design in medical research. Ann Intern Med 110, 560-566.

Zourdos, M.C., Dolan, C., Quiles, J.M., Klemp, A., Jo, E., Loenneke, J.P., Blanco, R., and Whitehurst, M. (2016). Efficacy of daily one-repetition maximum training in well-trained powerlifters and weightlifters: a case series. Nutrición Hospitalaria 33, 8. 
Figure 1

Overview of the study design

Overview of the study design. The session that was performed first, either the strengthoriented session or the power-oriented session, was randomized.

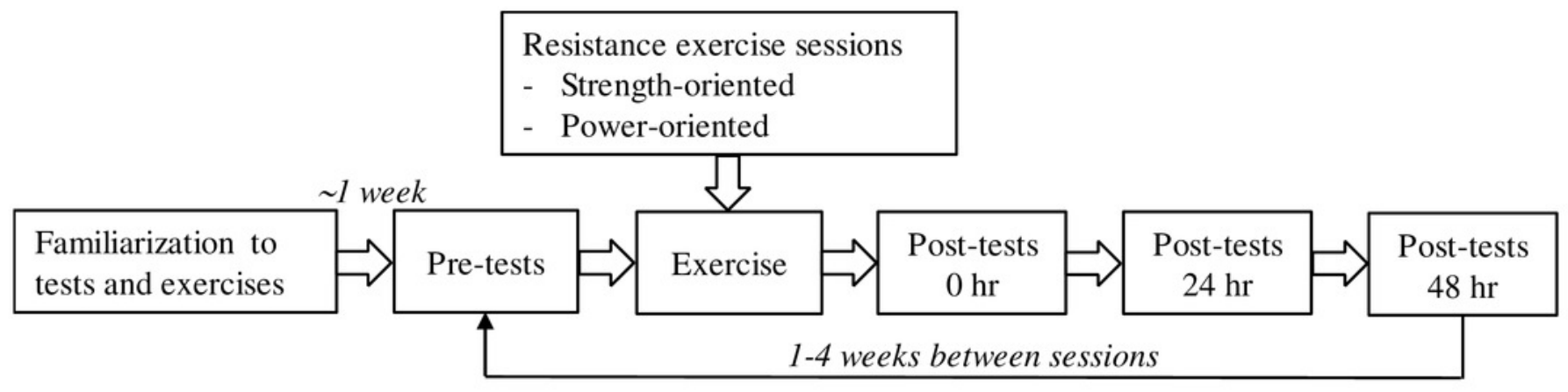


Figure 2

Force-time curve of a countermovement jump

An example of a force-time curve of a countermovement jump (CMJ). The eccentric and concentric phase are displayed.

RFD: Rate of Force Development

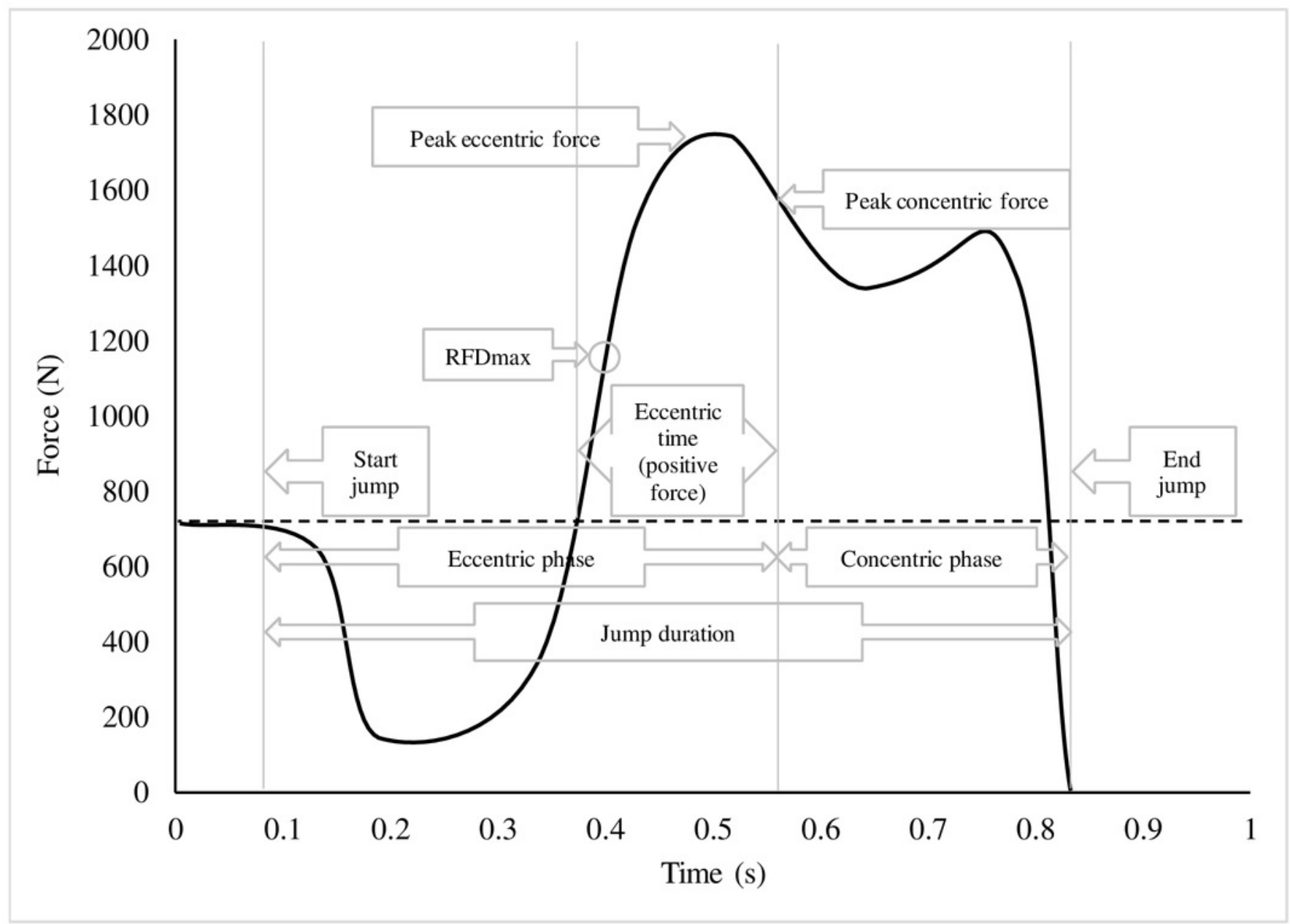




\section{Figure 3}

\section{Variables derived from the countermovement jump (CMJ) test}

Variables derived from the countermovement jump (CMJ) test obtained before, immediately after ( 0 hours) and 24 and 48 hours after the strength-oriented session and the power-oriented session. Values are means and $95 \% \mathrm{Cls}$ of percentage changes from pre-values. Changes within sessions and differences (Diff) between sessions are marked with effect sizes and $p$-values. Grey areas represent the smallest worthwhile change. A: Jump height, B: Peak power, C: Mean power, D: Peak concentric force, E: RFDmax, F: Eccentric time, G: Eccentric peak force, $\mathrm{H}$ : Depth (lowering of centre of mass).

RFDmax: Maximal Rate of Force Development. Trivial (Triv): <0.2, Small: 0.2-0.6; Moderate (Mod): 0.6-1.2; Large: 1.2-2.0; Very large: 2.0-4.0; Extremely large: <4.0 *: Possibly beneficial, **: Likely beneficial, ***: Very likely beneficial +: Possibly harmful, ++: Likely harmful, +++: Very likely harmful, ++++: Most likely harmful ${ }^{\circ}$ : Possibly trivial, ${ }^{00}$ : Likely trivial, ${ }^{000}$ : Very likely trivial, ${ }^{0000}$ : Most likely trivial ${ }^{\text {Uncl: }}$ Unclear a: $p<0.05$ b: $p<0.01$ 

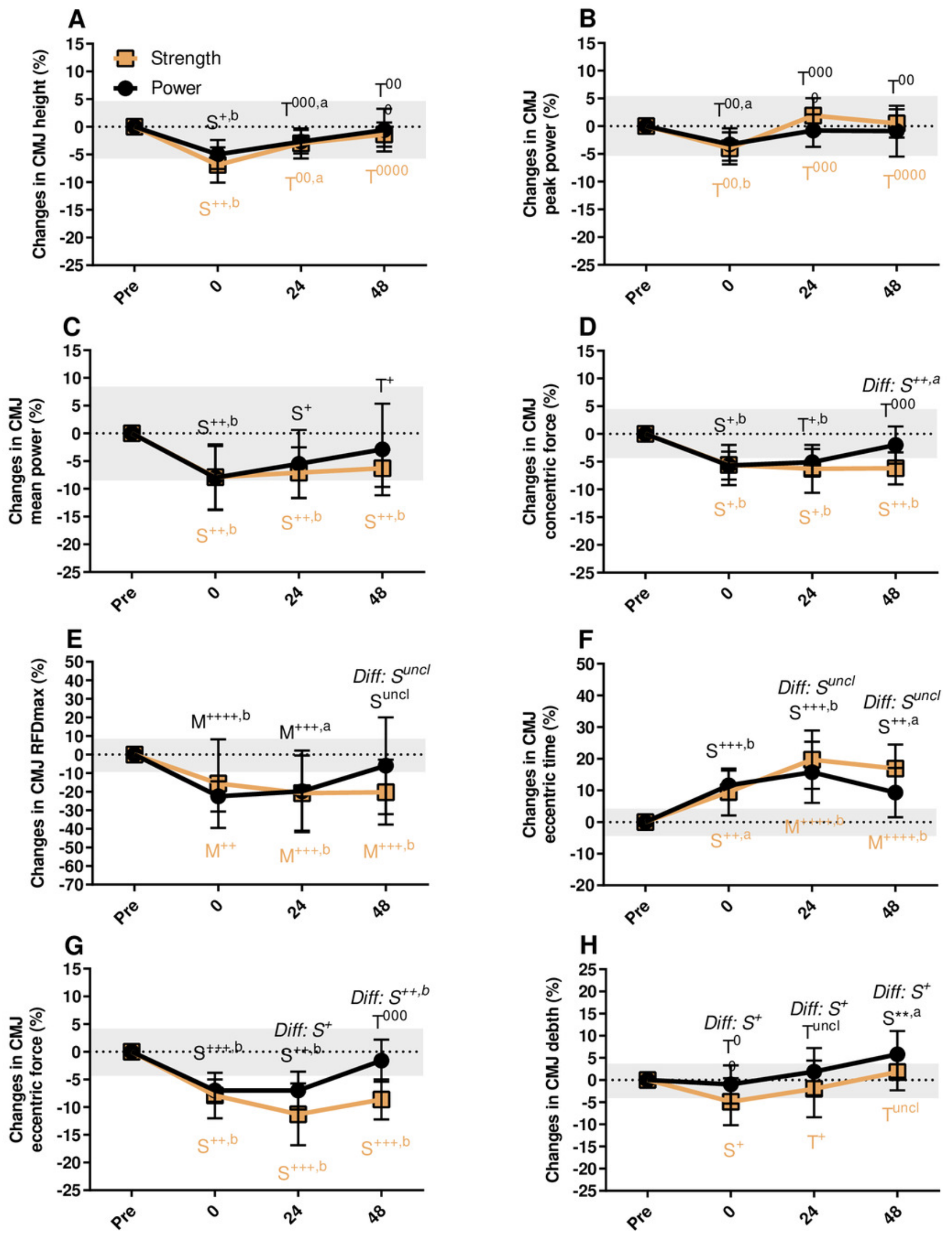
Figure 4

Objective vs. subjective measures

Figure 4. X-y-plots of individual values for the strength-oriented session and the poweroriented session; regression lines are given with 95\% confidence bands. A and B display the relationship between eccentric peak force and perceived recovery status (PRS; lower body) 24 and 48 hours after the sessions. C and D display the relationship between peak push-up force and PRS (upper body) 24 and 48 hours after the sessions. PRS values are given in the range $0-100$, where 100 is fully recovered
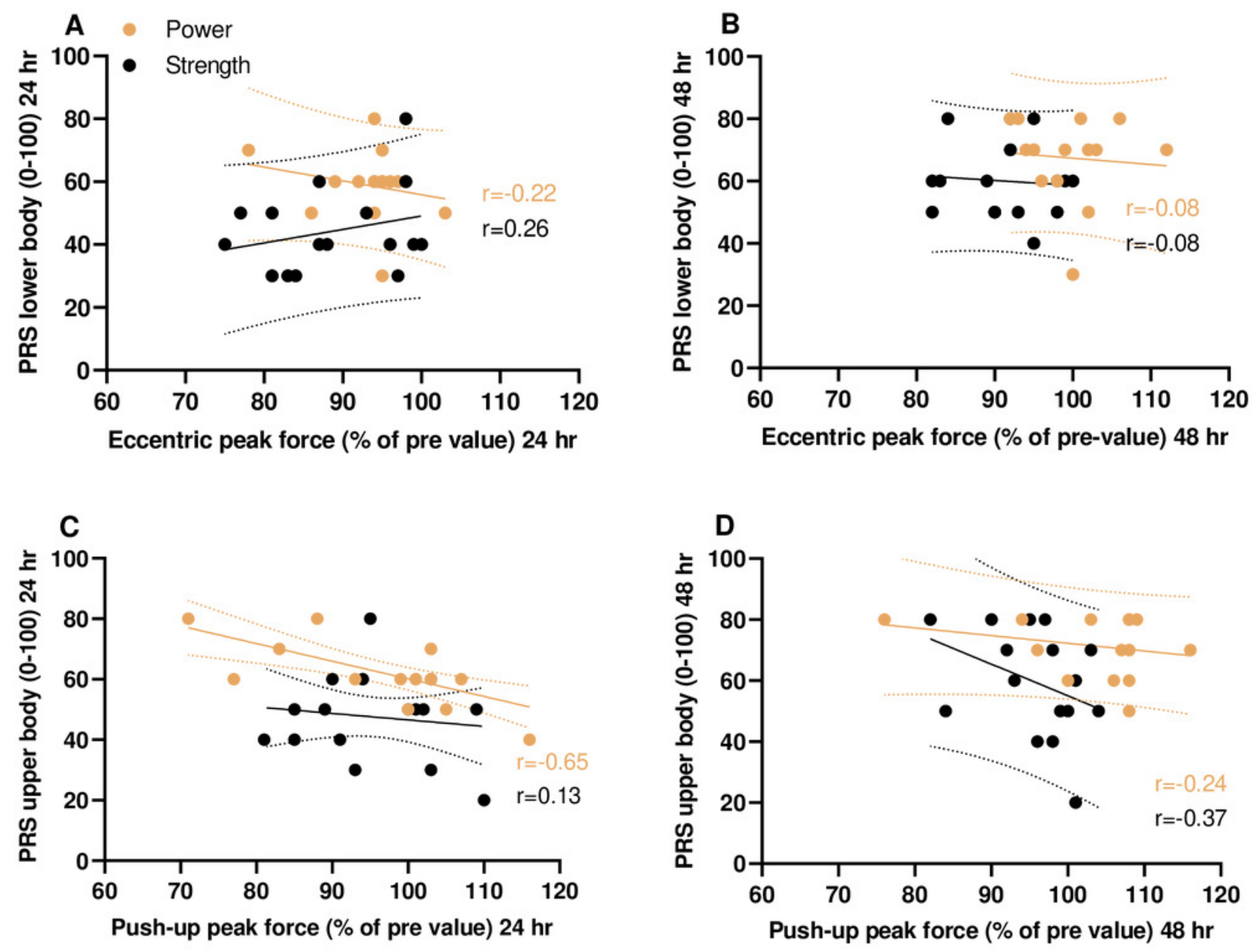


\section{Table 1 (on next page)}

The exercises applied

Exercises for each of the two sessions 
1

\begin{tabular}{ccc}
\hline Power session & $\begin{array}{c}\text { Heavy strength } \\
\text { session }\end{array}$ & Comment \\
\hline $\begin{array}{c}\text { Loaded CMJ } \\
\text { Trap bar CMJ } \\
\text { Trat with overhead push }\end{array}$ & $\begin{array}{c}\text { Squat } \\
\text { Front squat } \\
\text { Trap bar squat }\end{array}$ & $\begin{array}{c}\text { Same depth in the eccentric phase } \\
\text { Same depth in the eccentric phase } \\
\text { Same depth in the eccentric phase }\end{array}$ \\
$\begin{array}{c}\text { Bench press throw } \\
\text { arrow bench press throw } \\
\text { Explosive push-ups }\end{array}$ & $\begin{array}{c}\text { Bench press } \\
\text { Weighted push-ups }\end{array}$ & $\begin{array}{c}\text { Conducted in a Smith rack } \\
\text { Conducted in a Smith rack } \\
\text { Load by weight-vest (1-9 kg) and } \\
\text { discs (5-20 kg). Boxes (25 cm) } \\
\text { were placed under feet and hands. }\end{array}$ \\
\hline
\end{tabular}

2 
Table 2 (on next page)

Baseline values

Baseline values for the strength-oriented session and the power-oriented session. 


\begin{tabular}{|c|c|c|c|c|c|}
\hline Variable & $\begin{array}{l}\text { Power } \\
\text { Mean } \pm \text { SD }\end{array}$ & $\begin{array}{l}\text { Strength } \\
\text { Mean } \pm \text { SD }\end{array}$ & $\begin{array}{l}\text { SD used for } \\
\text { standardizing } \\
\text { (adjusted) }\end{array}$ & $\begin{array}{l}\text { Smallest } \\
\text { worthwhile } \\
\text { change \% } \\
(0.2 \text { SD) }\end{array}$ & $\begin{array}{l}\text { Coefficient } \\
\text { of } \\
\text { Variation } \\
\%(C V)\end{array}$ \\
\hline $\mathrm{CMJ}(\mathrm{cm})$ & $34.8 \pm 8.7$ & $34.7 \pm 9.0$ & 8.9 & 5.0 & 5.1 \\
\hline CMJ peak power $(\mathrm{W})$ & $1905 \pm 670$ & $1869 \pm 722$ & 703 & 7.5 & 6.5 \\
\hline CMJ mean power $(\mathrm{W})$ & $316 \pm 116$ & $317 \pm 128$ & 123 & 8.0 & 8.7 \\
\hline $\begin{array}{l}\text { CMJ concentric peak } \\
\text { force }(\mathrm{N})\end{array}$ & $1788 \pm 406$ & $1774 \pm 348$ & 381 & 4.3 & 4.0 \\
\hline CMJ RFDmax (N/s) & $\begin{array}{l}13169 \pm \\
5317\end{array}$ & $12843 \pm 5895$ & 5663 & 8.8 & 21.2 \\
\hline CMJ duration (s) & $0.84 \pm 0.08$ & $0.84 \pm 0.09$ & 0.09 & 2.1 & 7.4 \\
\hline $\begin{array}{l}\text { CMJ eccentric peak } \\
\text { force }(\mathrm{N})\end{array}$ & $1793 \pm 410$ & $1787 \pm 357$ & 378 & 4.4 & 4.2 \\
\hline CMJ eccentric time (s) & $0.18 \pm 0.04$ & $0.19 \pm 0.03$ & 0.04 & 3.8 & 9.9 \\
\hline CMJ depth $(\mathrm{cm})$ & $-39.2 \pm 6.0$ & $40.1 \pm 6.4$ & 6.3 & 3.2 & 8.3 \\
\hline $\mathrm{SJ}(\mathrm{cm})$ & $32.0 \pm 8.0$ & $32.3 \pm 8.2$ & 8.2 & 5.0 & 5.7 \\
\hline SJ peak power $(\mathrm{W})$ & $1980 \pm 672$ & $2003 \pm 748$ & 717 & 7.3 & 6.3 \\
\hline SJ mean power $(\mathrm{W})$ & $586 \pm 220$ & $606 \pm 254$ & 240 & 8.2 & 9.8 \\
\hline SJ peak force $(\mathrm{N})$ & $1630 \pm 326$ & $1637 \pm 361$ & 347 & 4.3 & 4.3 \\
\hline SJ RFDmax (N/s) & $7155 \pm 2090$ & $7675 \pm 3210$ & 2744 & 6.9 & 21.0 \\
\hline SJ duration (s) & $0.40 \pm 0.03$ & $0.40 \pm 0.05$ & 0.04 & 2.1 & 8.6 \\
\hline $\mathrm{MJ}(\mathrm{cm})$ & $27.6 \pm 6.8$ & $29.6 \pm 8.2$ & 7.7 & 5.2 & 9.1 \\
\hline MJ RSI & $45.2 \pm 12.0$ & $47.4 \pm 15.6$ & 14.1 & 6.0 & 14.9 \\
\hline $\begin{array}{l}\text { MJ vertical stiffness } \\
(\mathrm{N} / \mathrm{m})\end{array}$ & $6.0 \pm 1.9$ & $5.9 \pm 1.7$ & 1.8 & 6.0 & 19.9 \\
\hline $20 \mathrm{~m}(\mathrm{~s})$ & $3.08 \pm 0.22$ & $3.08 \pm 0.23$ & 0.23 & 1.5 & 1.3 \\
\hline Push-up peak force (N) & $1071 \pm 421$ & $1105 \pm 422$ & 425 & 7.1 & 11.2 \\
\hline Squat peak power $(\mathrm{W})$ & $1380 \pm 332$ & $1438 \pm 314$ & 327 & 4.8 & 7.2 \\
\hline $\begin{array}{l}\text { Bench press peak power } \\
\text { (W) }\end{array}$ & $433 \pm 180$ & $450 \pm 184$ & 184 & 9.4 & 9.3 \\
\hline $\begin{array}{l}\text { Squat estimated 1RM } \\
(\mathrm{kg})\end{array}$ & $121 \pm 39$ & $120 \pm 41$ & 39.9 & 6.6 & 4.6 \\
\hline $\begin{array}{l}\text { Bench press estimated } \\
1 \mathrm{RM}(\mathrm{kg})\end{array}$ & $80 \pm 29$ & $81 \pm 30$ & 30.0 & 7.5 & 3.3 \\
\hline PRS (\%) & $83.1 \pm 9.5$ & $76.9 \pm 10.1$ & 10.4 & 10 & 14.5 \\
\hline sRPE upper body $(0-10)$ & $5.1 \pm 1.5$ & $6.8 \pm 1.5$ & -- & 10 & -- \\
\hline sRPE lower body $(0-10)$ & $5.3 \pm 1.1$ & $7.4 \pm 1.3$ & -- & 10 & -- \\
\hline $\begin{array}{l}\text { Total work upper body } \\
\text { (kJ) }\end{array}$ & $12 \pm 7$ & $11 \pm 7$ & -- & -- & -- \\
\hline $\begin{array}{l}\text { Total work lower body } \\
(\mathrm{kJ})\end{array}$ & $57 \pm 14$ & $57 \pm 14$ & -- & -- & -- \\
\hline
\end{tabular}

$1 \mathrm{RM}=1$ Repetition Maximum, CMJ = Countermovement Jump, MJ = Multi Jump, PRS = Perceived

Recovery Status, RSI = Reactive Strength Index, RFDmax = Maximal Rate of Force Development, SJ =

Squat Jump, sRPE = session RPE 


\section{Table 3(on next page)}

Changes and recovery over time

Percent changes from baseline within the strength-oriented session and the power-oriented session, with $95 \% \mathrm{Cls}$ and associated effect sizes and inferences (adjusted for baseline values). 


\begin{tabular}{|c|c|c|c|c|c|c|c|}
\hline Variable & & $\begin{array}{l}\text { Post } 0 \\
0 \text { hours } \\
\text { Mean } \pm \text { SD; } \\
\pm 95 \% \text { CI } \\
\end{array}$ & Inference & $\begin{array}{l}\text { Post } 1 \\
24 \text { hours } \\
\text { Mean } \pm \text { SD; } \\
\pm 95 \% \text { CI } \\
\end{array}$ & Inference & $\begin{array}{l}\text { Post } 2 \\
48 \text { hours } \\
\text { Mean } \pm \text { SD; } \\
\pm 95 \% \text { CI } \\
\end{array}$ & Inference \\
\hline SJ height & $\begin{array}{l}\text { Power } \\
\text { Strength }\end{array}$ & $\begin{array}{l}-4.2 \pm 3.8 ; \pm 1.9 \\
-8.2 \pm 5.8 ; \pm 2.8\end{array}$ & $\begin{array}{l}\operatorname{Triv}^{00}(\mathrm{p}<.05) \\
\text { Small }^{+++} \\
(\mathrm{p}<.05 / 01)\end{array}$ & $\begin{array}{l}-1.2 \pm 3.9 ; \pm 2.1 \\
-3.7 \pm 6.5 ; \pm 3.3\end{array}$ & $\begin{array}{l}\text { Triv }^{0000} \\
\text { Triv } \\
(\mathrm{p}<.05)\end{array}$ & $\begin{array}{l}0.7 \pm 4.4 ; \pm 2.4 \\
-2.1 \pm 6.7 ; \pm 3.4\end{array}$ & $\begin{array}{l}\text { Triv } 0000 \\
\text { Triv }^{000}\end{array}$ \\
\hline SJ peak power & $\begin{array}{l}\text { Power } \\
\text { Strength }\end{array}$ & $\begin{array}{l}-2.9 \pm 4.3 ; \pm 2.2 \\
-4.3 \pm 4.8 ; \pm 2.4\end{array}$ & $\begin{array}{l}\text { Triv } \\
(\mathrm{p}<.05) \\
\text { Triv }^{+} \\
(\mathrm{p}<.05 / 01)\end{array}$ & $\begin{array}{l}-1.5 \pm 5.6 ; \pm 2.9 \\
-2.6 \pm 9.4 ; \pm 4.7\end{array}$ & $\begin{array}{l}\text { Triv }^{000} \\
\text { Triv }^{00}\end{array}$ & $\begin{array}{l}-1.1 \pm 7.0 ; \pm 3.7 \\
-3.8 \pm 8.6 ; \pm 4.3\end{array}$ & $\begin{array}{l}\text { Triv }^{000} \\
\text { Triv }^{+}\end{array}$ \\
\hline SJ mean power & $\begin{array}{l}\text { Power } \\
\text { Strength }\end{array}$ & $\begin{array}{l}-5.9 \pm 7.9 ; \pm 3.8 \\
-11.5 \pm 12.9 ; \pm 5.8\end{array}$ & $\begin{array}{l}\text { Small }^{+} \\
(\mathrm{p}<.05 / 01) \\
\text { Small } \\
(\mathrm{p}<.05 / 01)\end{array}$ & $\begin{array}{l}-5.4 \pm 11.8 ; \pm 5.7 \\
-7.8 \pm 14.1 ; \pm 6.5\end{array}$ & $\begin{array}{l}\mathrm{Small}^{+} \\
\mathrm{Small}^{++} \\
(\mathrm{p}<.05\end{array}$ & $\begin{array}{l}-1.5 \pm 12.9 ; \pm 6.7 \\
-6.3 \pm 15.1 ; \pm 7.1\end{array}$ & $\begin{array}{l}\text { Triv uncl } \\
\text { Small }^{+}\end{array}$ \\
\hline SJ peak force & $\begin{array}{l}\text { Power } \\
\text { Strength }\end{array}$ & $\begin{array}{l}-0.7 \pm 3.2 ; \pm 1.7 \\
-0.6 \pm 3.0 ; \pm 1.6\end{array}$ & $\begin{array}{l}\text { Triv }^{0000} \\
\text { Triv }^{0000}\end{array}$ & $\begin{array}{l}-0.9 \pm 3.7 ; \pm 1.9 \\
-1.2 \pm 5.8 ; \pm 3.0\end{array}$ & $\begin{array}{l}\text { Triv }^{0000} \\
\text { Triv }^{000}\end{array}$ & $\begin{array}{l}-1.4 \pm 4.3 ; \pm 2.3 \\
-2.7 \pm 4.6 ; \pm 2.4\end{array}$ & $\begin{array}{l}\text { Triv }{ }^{0000} \\
\text { Triv } 000 \\
(\mathrm{p}<.05)\end{array}$ \\
\hline SJ RFDmaks & $\begin{array}{l}\text { Power } \\
\text { Strength }\end{array}$ & $\begin{array}{l}-4.4 \pm 15.3 ; \pm 7.3 \\
-7.0 \pm 17.3 ; \pm 8.0\end{array}$ & $\begin{array}{l}\text { Triv }^{+} \\
\text {Small }^{+}\end{array}$ & $\begin{array}{l}0.0 \pm 16.0 ; \pm 7.9 \\
-11.5 \pm 28.1 ; \\
\pm 11.8\end{array}$ & $\begin{array}{l}\text { Triv } \\
\text { Small }^{++}\end{array}$ & $\begin{array}{l}4.2 \pm 17.5 ; \pm 9.4 \\
-7.3 \pm 32.9 ; \pm 14.2\end{array}$ & $\begin{array}{l}\text { Trivuncl } \\
\text { Small }^{+}\end{array}$ \\
\hline SJ duration & $\begin{array}{l}\text { Power } \\
\text { Strength }\end{array}$ & $\begin{array}{l}1.9 \pm 6.8 ; \pm 3.6 \\
5.3 \pm 8.8 ; \pm 4.8\end{array}$ & $\begin{array}{l}\text { Triv } 000 \\
\text { Small+ } \\
(\mathrm{p}<.05)\end{array}$ & $\begin{array}{l}4.1 \pm 9.8 ; \pm 5.2 \\
5.5 \pm 9.8 ; \pm 5.3\end{array}$ & $\begin{array}{l}\text { Triv }^{+} \\
\text {Small+ } \\
(\mathrm{p}<.05)\end{array}$ & $\begin{array}{l}1.7 \pm 9.5 ; \pm 5.1 \\
4.4 \pm 9.8 ; \pm 5.2\end{array}$ & $\begin{array}{l}\text { Triv }^{00} \\
\text { Triv }^{+}\end{array}$ \\
\hline MJ heigth & $\begin{array}{l}\text { Power } \\
\text { Strength }\end{array}$ & $\begin{array}{l}2.4 \pm 12.4 ; \pm 6.4 \\
-3.2 \pm 10.0 ; \pm 4.1\end{array}$ & $\begin{array}{l}\text { Triv }{ }^{\text {uncl }} \\
\text { Triv }\end{array}$ & $\begin{array}{l}6.4 \pm 9.3 ; \pm 5.3 \\
-0.5 \pm 8.4 ; \pm 3.5\end{array}$ & $\begin{array}{l}\text { Small* }^{*} \\
(\mathrm{p}<.05) \\
\text { Triv }^{000}\end{array}$ & $\begin{array}{l}4.4 \pm 10.7 ; \pm 5.7 \\
1.4 \pm 4.8 ; \pm 2.1\end{array}$ & $\begin{array}{l}\text { Triv* } \\
\text { Triv }^{0000}\end{array}$ \\
\hline MJ RSI & $\begin{array}{l}\text { Power } \\
\text { Strength }\end{array}$ & $\begin{array}{l}-2.5 \pm 14.7 ; \pm 7.2 \\
-6.3 \pm 11.4 ; \pm 5.4\end{array}$ & $\begin{array}{l}\text { Triv }^{00} \\
\text { Small }^{+} \\
(\mathrm{p}<.05)\end{array}$ & $\begin{array}{l}4.1 \pm 11.3 ; \pm 6.2 \\
-0.7 \pm 7.3 ; \pm 3.8\end{array}$ & $\begin{array}{l}\text { Small }^{\text {uncl }} \\
\text { Triv }^{000}\end{array}$ & $\begin{array}{l}1.1 \pm 11.3 ; \pm 5.8 \\
1.6 \pm 8.3 ; \pm 4.4\end{array}$ & $\begin{array}{l}\text { Triv } \\
\text { Triv }^{000}\end{array}$ \\
\hline $\begin{array}{l}\text { MJ vertical } \\
\text { stiffness }\end{array}$ & $\begin{array}{l}\text { Power } \\
\text { Strength }\end{array}$ & $\begin{array}{l}2.8 \pm 19.9 ; \pm 10.4 \\
0.4 \pm 11.6 ; \pm 6.2\end{array}$ & $\begin{array}{l}\text { Triv } \\
\text { Trivel }^{00} \\
\end{array}$ & $\begin{array}{l}-5.3 \pm 18.0 ; \pm 9.1 \\
5.3 \pm 10.5 ; \pm 5.8 \\
\end{array}$ & $\begin{array}{l}\text { Small }^{+} \\
\text {Small* }\end{array}$ & $\begin{array}{l}-5.2 \pm 24.4 ; \pm 11.6 \\
-1.1 \pm 15.2 ; \pm 7.8 \\
\end{array}$ & $\begin{array}{l}\text { Small }^{+} \\
\text {Triv }^{00} \\
\end{array}$ \\
\hline $20 \mathrm{~m}$ & $\begin{array}{l}\text { Power } \\
\text { Strength }\end{array}$ & $\begin{array}{l}0.0 \pm 1.8 ; \pm 1.0 \\
1.5 \pm 1.8 ; \pm 1.0\end{array}$ & $\begin{array}{l}\text { Triv0000 } \\
\text { Triv }^{+}(\mathrm{p}<.05)\end{array}$ & $\begin{array}{l}0.7 \pm 1.6 ; \pm 0.8 \\
1.2 \pm 1.9 ; \pm 1.1\end{array}$ & $\begin{array}{l}\text { Triv }{ }^{000} \\
\text { Triv }^{+} \\
(\mathrm{p}<.05)\end{array}$ & $\begin{array}{l}0.6 \pm 1.7 ; \pm 0.9 \\
0.5 \pm 1.7 ; \pm 1.0\end{array}$ & $\begin{array}{l}\text { Triv }^{000} \\
\text { Triv }^{000}\end{array}$ \\
\hline $\begin{array}{l}\text { Push-up peak } \\
\text { force }\end{array}$ & $\begin{array}{l}\text { Power } \\
\text { Strength }\end{array}$ & $\begin{array}{l}-0.6 \pm 12.0 ; \pm 6.1 \\
-1.0 \pm 7.3 ; \pm 3.1\end{array}$ & $\begin{array}{l}\text { Triv } \\
\text { Triv }^{0000}\end{array}$ & $\begin{array}{l}-4.8 \pm 14.4 ; \pm 7.5 \\
-4.7 \pm 9.6 ; \pm 3.9\end{array}$ & $\begin{array}{l}\text { Triv }^{+} \\
\text {Triv }^{00}\end{array}$ & $\begin{array}{l}5.2 \pm 14.4 ; \pm 8.6 \\
-4.3 \pm 7.1 ; \pm 2.9\end{array}$ & $\begin{array}{l}\text { Triv }{ }^{\text {uncl }} \\
\text { Triv }^{00}\end{array}$ \\
\hline Squat peak power & $\begin{array}{l}\text { Power } \\
\text { Strength }\end{array}$ & $\begin{array}{ll}- \\
--\end{array}$ & $\begin{array}{l}-- \\
--\end{array}$ & $\begin{array}{l}2.9 \pm 9.0 ; \pm 4.7 \\
-6.4 \pm 7.6 ; \pm 3.7\end{array}$ & $\begin{array}{l}\text { Triv }^{00} \\
\text { Small }^{++} \\
(\mathrm{p}<.05 / 01)\end{array}$ & $\begin{array}{l}5.8 \pm 6.7 ; \pm 3.8 \\
-3.7 \pm 8.3 ; \pm 4.7\end{array}$ & $\begin{array}{l}\text { Small* } \\
(\mathrm{p}<.05) \\
\text { Triv }^{+}\end{array}$ \\
\hline $\begin{array}{l}\text { Bench press peak } \\
\text { power }\end{array}$ & $\begin{array}{l}\text { Power } \\
\text { Strength }\end{array}$ & $\begin{array}{l}- \\
--\end{array}$ & $\begin{array}{l}- \\
--\end{array}$ & $\begin{array}{l}-0.1 \pm 5.3 ; \pm 3.0 \\
-5.6 \pm 6.3 ; \pm 3.4\end{array}$ & $\begin{array}{l}\text { Triv }^{0000} \\
\text { Triv }^{000} \\
(\mathrm{p}<.05 / 01)\end{array}$ & $\begin{array}{l}3.5 \pm 8.9 ; \pm 5.2 \\
-2.6 \pm 10.7 ; \pm 6.4\end{array}$ & $\begin{array}{l}\text { Triv }^{000} \\
\text { Triv }^{000}\end{array}$ \\
\hline $\begin{array}{l}\text { Squat estimated } \\
1 \mathrm{RM}\end{array}$ & $\begin{array}{l}\text { Power } \\
\text { Strength }\end{array}$ & $\begin{array}{l}- \\
--\end{array}$ & $\begin{array}{l}- \\
-- \\
\end{array}$ & $\begin{array}{l}-1.6 \pm 6.2 ; \pm 3.2 \\
-0.5 \pm 5.7 ; \pm 3.0\end{array}$ & $\begin{array}{l}\text { Triv }^{0000} \\
\text { Triv }^{0000}\end{array}$ & $\begin{array}{l}-1.3 \pm 5.5 ; \pm 2.9 \\
-2.5 \pm 4.8 ; \pm 2.8\end{array}$ & $\begin{array}{l}\text { Triv } 0000 \\
\text { Triv }^{0000}\end{array}$ \\
\hline $\begin{array}{l}\text { Bench press } \\
\text { estimated 1RM }\end{array}$ & $\begin{array}{l}\text { Power } \\
\text { Strength }\end{array}$ & $\begin{array}{l}- \\
--\end{array}$ & $\begin{array}{l}-- \\
--\end{array}$ & $\begin{array}{l}-1.6 \pm 4.8 ; \pm 2.7 \\
-3.2 \pm 5.4 ; \pm 3.0\end{array}$ & $\begin{array}{l}\text { Triv }{ }^{0000} \\
\text { Triv }^{000} \\
(\mathrm{p}<.05) \\
\end{array}$ & $\begin{array}{l}-1.1 \pm 3.9 ; \pm 2.2 \\
-2.8 \pm 5.0 ; \pm 3.1\end{array}$ & $\begin{array}{l}\text { Triv } \\
\text { Triv } \\
\text { To000 }\end{array}$ \\
\hline PRS total & $\begin{array}{l}\text { Power } \\
\text { Strength }\end{array}$ & $\begin{array}{l}-36.9 \pm 16.5 ; \pm 8.9 \\
-44.1 \pm 15.6 ; \pm 8.4\end{array}$ & $\begin{array}{l}\operatorname{Mod}^{++++} \\
(\mathrm{p}<.05 / 01) \\
\operatorname{Mod}^{++++} \\
(\mathrm{p}<.05 / 01)\end{array}$ & $\begin{array}{l}-23.8 \pm 8.7 ; \pm 4.7 \\
(p<.05 / 01) \\
-30.0 \pm 11.9 ; \pm 6.4 \\
(p<.05 / 01) \\
\end{array}$ & $\begin{array}{l}\text { Small } \\
\text { Mod }^{+++++}\end{array}$ & $\begin{array}{l}-13.6 \pm 9.1 ; \pm 4.7 \\
(p<.05 / 01) \\
-16.3 \pm 14.7 ; \pm 7.9 \\
(p<.05 / 01) \\
\end{array}$ & $\begin{array}{l}\text { Small } \\
\text { Small }^{+++}\end{array}$ \\
\hline PRS upper body & $\begin{array}{l}\text { Power } \\
\text { Strength }\end{array}$ & $\begin{array}{l}-38.1 \pm 17.5 ; \pm 9.4 \\
-43.8 \pm 11.7 ; \pm 6.2\end{array}$ & $\begin{array}{l}\operatorname{Mod}^{++++} \\
(\mathrm{p}<.05 / 01) \\
\operatorname{Mod}^{++++} \\
(\mathrm{p}<.05 / 01)\end{array}$ & $\begin{array}{l}-21.3 \pm 10.4 ; \pm 5.6 \\
(p<.05 / 01 \\
-29.4 \pm 10.3 ; \pm 5.5 \\
(p<.05 / 01)\end{array}$ & $\begin{array}{l}\text { Small } \\
\text { Small }^{+++++}\end{array}$ & $\begin{array}{l}-11.3 \pm 8.8 ; \pm 4.7 \\
(p<.05 / 01 \\
-17.5 \pm 18.1 ; \pm 9.7 \\
(p<.05 / 01)\end{array}$ & $\begin{array}{l}\text { Small }^{+} \\
\text {Small }^{++}\end{array}$ \\
\hline PRS lower body & $\begin{array}{l}\text { Power } \\
\text { Strength }\end{array}$ & $\begin{array}{l}-40.6 \pm 14.5 ; \pm 7.8 \\
-45.0 \pm 13.6 ; \pm 7.3\end{array}$ & $\begin{array}{l}\operatorname{Mod}^{++++} \\
(\mathrm{p}<.05 / 01) \\
\operatorname{Mod}^{++++} \\
(\mathrm{p}<.05 / 01)\end{array}$ & $\begin{array}{l}-24.4 \pm 11.3 ; \pm 6.0 \\
(\mathrm{p}<.05 / 01) \\
-32.5 \pm 13.3 ; \pm 7.1 \\
(\mathrm{p}<.05 / 01)\end{array}$ & $\begin{array}{l}\text { Small } \\
\text { Mod }^{+++++}\end{array}$ & $\begin{array}{l}-15.6 \pm 13.0 ; \pm 7.0 \\
(p<.05 / 01) \\
-16.9 \pm 12.5 ; \pm 6.7 \\
(p<.05 / 01)\end{array}$ & $\begin{array}{l}\text { Small } \\
\text { Small }^{++}\end{array}$ \\
\hline
\end{tabular}

$1 \mathrm{RM}=1$ Repetition Maximum, CI: Confidence Interval, MJ = Multi Jump, PRS = Perceived Recovery Status, RSI = Reactive Strength Index,

RFDmax $=$ Maximal Rate of Force Development, SD: Standard Deviation, SJ $=$ Squat Jump, sRPE $=$ session RPE

Trivial (Triv): $<0.2$, Small: 0.2-0.6; Moderate (Mod): 0.6-1.2; Large: 1.2-2.0; Very large: 2.0-4.0; Extremely large: <4.0

*: Possibly beneficial, **: Likely beneficial, ***: Very likely beneficial

${ }^{+}$: Possibly harmful, ${ }^{++}$: Likely harmful, ${ }^{+++}$: Very likely harmful, ${ }^{++++}$: most likely harmful

${ }^{0}$ : Possibly trivial, ${ }^{00}$ : Likely trivial, ${ }^{000}$ : Very likely trivial, ${ }^{0000}$ : Most likely trivial

uncl: Unclear (need more data)

$\mathrm{p}<.05$ : The $95 \%$ CI do not overlap with zero

$\mathrm{p}<.01$ : The $99 \% \mathrm{CI}$ do not overlap with zero 


\section{Table 4(on next page)}

Differences between sessions

Percent differences between the strength-oriented session and the power-oriented session at 0, 24 and 48 hours, with 95\% Cls and associated effect sizes and inferences (strength minus power; adjusted for baseline values). 


\begin{tabular}{|c|c|c|c|c|c|c|}
\hline Variable & $\begin{array}{l}\text { Post 0 } \\
\text { 0 hours } \\
\text { Mean; } \\
\pm 95 \% \text { CI }\end{array}$ & Inference & $\begin{array}{l}\text { Post } 1 \\
24 \text { hours } \\
\text { Mean; } \\
\pm 95 \% \text { CI }\end{array}$ & Inference & $\begin{array}{l}\text { Post } 2 \\
48 \text { hours } \\
\text { Mean; } \\
\pm 95 \% \text { CI }\end{array}$ & Inference \\
\hline SJ height & $-4.1 ; \pm 3.4$ & $\operatorname{Triv}^{+}(\mathrm{p}<.05)$ & $-2.5 ; \pm 3.8$ & Triv $^{00}$ & $-2.8 ; \pm 3.6$ & Triv $^{00}$ \\
\hline SJ peak power & $-1.4 ; \pm 3.5$ & Triv 0000 & $-1.1 ; \pm 5.2$ & Triv $^{000}$ & $-2.7 ; \pm 5.3$ & Triv $^{000}$ \\
\hline SJ mean power & $-6.0 ; \pm 5.7$ & $\operatorname{Triv}^{00}(\mathrm{p}<.05)$ & $-2.5 ; \pm 8.4$ & Triv $^{00}$ & $-4.8 ; \pm 9.9$ & Triv $^{+}$ \\
\hline SJ peak force & $0.1 ; \pm 2.4$ & Triv $^{0000}$ & $-0.3 ; \pm 3.4$ & Triv 000 & $-1.3 ; \pm 3.1$ & Triv ${ }^{000}$ \\
\hline SJ RFD max & $-1.8 ; \pm 11.4$ & Triv $^{0}$ & $-11.3 ; \pm 13.7$ & Small $^{++}$ & $-10.5 ; \pm 15.0$ & Small $^{+}$ \\
\hline SJ duration & $2.9 ; \pm 5.3$ & Small $^{+}$ & $0.4 ; \pm 6.8$ & Triv uncl & $1.7 ; \pm 7.5$ & Triv uncl \\
\hline MJ height & $-5.1 ; \pm 8.5$ & Small $^{+}$ & $-6.0 ; \pm 6.3$ & Small $^{+}$ & $-1.7 ; \pm 5.3$ & Triv 00 \\
\hline MJ RSI & $-3.5 ; \pm 9.0$ & Triv $^{+}$ & $-4.2 ; \pm 6.5$ & Triv $^{+}$ & $1.2 ; \pm 5.6$ & Triv $^{000}$ \\
\hline MJ vertical stiffness & $-2.7 ; \pm 9.7$ & Triv $^{+}$ & $10.8 ; \pm 12.4$ & Small** & $4.0 ; \pm 10.7$ & Triv ${ }^{\text {uncl }}$ \\
\hline $20 \mathrm{~m}$ & $1.4 ; \pm 1.0$ & Triv $^{+}$ & $0.5 ; \pm 1.2$ & Triv $^{00}$ & $-0.1 ; \pm 1.1$ & Triv 000 \\
\hline Push-up peak force & $-0.3 ; \pm 7.8$ & Triv uncl & $0.4 ; \pm 9.3$ & Triv 00 & $-9.0 ; \pm 8.9$ & $\mathrm{Small}^{+}(\mathrm{p}<.05)$ \\
\hline Squat peak power & -- & -- & $-9.1 ; \pm 5.6$ & $\begin{array}{l}\text { Small }^{++} \\
(\mathrm{p}<.05 / 01)\end{array}$ & $-8.8 ; \pm 5.5$ & $\operatorname{Small}^{++}(\mathrm{p}<.05 / 01)$ \\
\hline $\begin{array}{l}\text { Bench press peak } \\
\text { power }\end{array}$ & -- & -- & $-5.3 ; \pm 4.7$ & $\begin{array}{l}\text { Triv }{ }^{00} \\
(\mathrm{p}<.05)\end{array}$ & $-5.7 ; \pm 7.7$ & Triv $^{+}$ \\
\hline Squat estimated 1RM & -- & -- & $1.1 ; \pm 3.1$ & Triv 0000 & $-1.2 ; \pm 4.2$ & Triv 000 \\
\hline $\begin{array}{l}\text { Bench press estimated } \\
\text { 1RM }\end{array}$ & -- & -- & $-1.6 ; \pm 3.4$ & Triv0000 & $-1.7 ; \pm 4.5$ & Triv 000 \\
\hline sRPE total & $-20.6 ; \pm 10.1$ & $\begin{array}{l}\text { Small }{ }^{+++} \\
(\mathrm{p}<.05 / 01)\end{array}$ & -- & -- & -- & -- \\
\hline sRPE upper body & $-16.9 ; \pm 10.7$ & $\begin{array}{l}\text { Small } \\
(\mathrm{p}<.05 / 01)\end{array}$ & -- & -- & -- & -- \\
\hline sRPE lower body & $-21.9 ; \pm 8.8$ & $\begin{array}{l}\text { Small }{ }^{+++} \\
(\mathrm{p}<.05 / 01)\end{array}$ & -- & -- & -- & -- \\
\hline PRS total & $-11.1 ; \pm 7.0$ & $\begin{array}{l}\text { Small }^{+} \\
(\mathrm{p}<.05 / 01)\end{array}$ & $-10.1 ; \pm 9.2$ & $\begin{array}{l}\text { Small }^{+} \\
(\mathrm{p}<.05)\end{array}$ & $-6.8 ; \pm 10.4$ & Triv $^{+}$ \\
\hline PRS upper body & $-9.4 ; \pm 4.8$ & $\operatorname{Triv}^{+}(\mathrm{p}<.05 / 01)$ & $-10.2 ; \pm 8.8$ & $\begin{array}{l}\text { Small } \\
(\mathrm{p}<.05)\end{array}$ & $-10.1 ; \pm 10.9$ & Small $^{+}$ \\
\hline PRS lower body & $-8.5 ; \pm 6.6$ & $\operatorname{Triv}^{+}(\mathrm{p}<.05)$ & $-12.8 ; \pm 11.2$ & $\begin{array}{l}\text { Small }^{+} \\
(\mathrm{p}<.05)\end{array}$ & $-6.1 ; \pm 10.8$ & Triv $^{00}$ \\
\hline
\end{tabular}

$1 \mathrm{RM}=1$ Repetition Maximum, CI: Confidence Interval, MJ = Multi Jump, PRS = Perceived Recovery Status, RSI = Reactive Strength Index, RFDmax = Maximal Rate of Force Development, SD: Standard Deviation, SJ = Squat Jump, sRPE = session RPE

Trivial (Triv): $<0.2$, Small: 0.2-0.6; Moderate (Mod): 0.6-1.2; Large: 1.2-2.0; Very large: 2.0-4.0; Extremely large: $<4.0$

*: Possibly beneficial, **: Likely beneficial, ***: Very likely beneficial

${ }^{+}$: Possibly harmful, ${ }^{++}$: Likely harmful, ${ }^{+++}$: Very likely harmful, ${ }^{+++}$: Most likely harmful

${ }^{0}$ : Possibly trivial, ${ }^{00}$ : Likely trivial, ${ }^{000}$ : Very likely trivial, ${ }^{0000}$ : Most likely trivial

uncl: Unclar (need more data)

$\mathrm{p}<.05$ : The $95 \% \mathrm{CI}$ do not overlap with zero

$\mathrm{p}<.01$ : The $99 \%$ CI do not overlap with zero

3

4 